\title{
A neural network approach for the simultaneous retrieval of volcanic ash parameters and $\mathrm{SO}_{2}$ using MODIS data
}

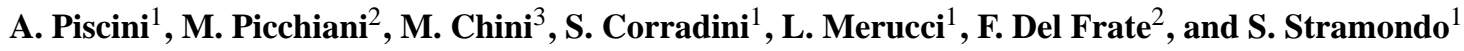 \\ ${ }^{1}$ Istituto Nazionale di Geofisica e Vulcanologia, Rome, Italy \\ ${ }^{2}$ Earth Observation Laboratory, D.I.C.I.I. - University of Tor Vergata, Rome, Italy \\ ${ }^{3}$ Centre de Recherche Public - Gabriel Lippmann, Belvaux, Luxembourg \\ Correspondence to: A. Piscini (alessandro.piscini@ingv.it)
}

Received: 20 February 2014 - Published in Atmos. Meas. Tech. Discuss.: 4 April 2014

Revised: 14 August 2014 - Accepted: 27 October 2014 - Published: 1 December 2014

\begin{abstract}
In this work neural networks (NNs) have been used for the retrieval of volcanic ash and sulfur dioxide $\left(\mathrm{SO}_{2}\right)$ parameters based on Moderate Resolution Imaging Spectroradiometer (MODIS) multispectral measurements. Different neural networks were built in order for each parameter to be retrieved, for experimenting with different topologies and evaluating their performances. The neural networks' capabilities to process a large amount of new data in a very fast way have been exploited to propose a novel applicative scheme aimed at providing a complete characterization of eruptive products.

As a test case, the May 2010 Eyjafjallajókull eruption has been considered. A set of seven MODIS images have been used for the training and validation phases.

In order to estimate the parameters associated to the volcanic eruption, such as ash mass, effective radius, aerosol optical depth and $\mathrm{SO}_{2}$ columnar abundance, the neural networks have been trained using the retrievals from wellknown algorithms. These are based on simulated radiances at the top of the atmosphere and are estimated by radiative transfer models.

Three neural network topologies with a different number of inputs have been compared: (a) three thermal infrared MODIS channels, (b) all multispectral MODIS channels and (c) the channels selected by a pruning procedure applied to all MODIS channels.

Results show that the neural network approach is able to estimate the volcanic eruption parameters very well, showing a root mean square error (RMSE) below the target data standard deviation (SD). The network built considering all the MODIS channels gives a better performance in terms of
\end{abstract}

specialization, mainly on images close in time to the training ones, while the networks with less inputs reveal a better generalization performance when applied to independent data sets. In order to increase the network's generalization capability and to select the most significant MODIS channels, a pruning algorithm has been implemented. The pruning outcomes revealed that channel sensitive to ash parameters correspond to the thermal infrared, visible and mid-infrared spectral ranges.

The neural network approach has been proven to be effective when addressing the inversion problem for the estimation of volcanic ash and $\mathrm{SO}_{2}$ cloud parameters, providing fast and reliable retrievals, important requirements during volcanic crises.

\section{Introduction}

The Eyjafjallajókull volcanic eruption which occurred in Iceland between April and May 2010 revealed once more the importance of the effects produced by this natural hazard (Zehner, 2010) and demonstrated how crucial a reliable realtime monitoring and tracking of volcanic clouds is. In particular, volcanic ash affects climate (Robock, 2000), human safety (Horwell and Baxter, 2006) and represents a severe threat to aviation (Miller and Casadevall, 2000). Furthermore, $\mathrm{SO}_{2}$ is considered as volcanic ash proxy when the latter is undetectable, having long-term effects on aircraft engines and covering an important role in volcanic processes (Allard et al., 1994; Wallace, 2001; Edmonds et al., 2010). 
Table 1. MODIS TIR channels' characteristics.

\begin{tabular}{cccc}
\hline Channel no. & $\begin{array}{c}\text { Center } \\
\text { wavelength }(\mu \mathrm{m})\end{array}$ & $\begin{array}{c}\text { NEDT } \\
(\mathrm{K})\end{array}$ & $\begin{array}{c}\text { Spatial } \\
\text { resolution }(\mathrm{km})\end{array}$ \\
\hline 28 & 7.3 & 0.25 & 1 \\
29 & 8.5 & 0.05 & 1 \\
30 & 9.7 & 0.25 & 1 \\
31 & 11.0 & 0.05 & 1 \\
32 & 12.0 & 0.05 & 1 \\
\hline
\end{tabular}

NEDT - Noise equivalent differential temperature

Although the ash detection algorithm is quite fast, the well-known methods used for the simultaneous quantitative estimation of ash and $\mathrm{SO}_{2}$, based on comparisons between top-of-the-atmosphere (TOA) radiance and the simulated one obtained using a radiative transfer model (RTM), require a high computational time and many parameters as input (see Sect. 3 for details), making the near realtime application of the standard retrieval procedures difficult during volcanic crises. With this in mind, in this study we propose a retrieval approach able to quantitatively estimate ash and $\mathrm{SO}_{2}$ parameters in near-realtime and achieving the same accuracy as when a RTM-based one is used.

The neural network approach has demonstrated its effectiveness in geophysics, and is considered to be an universal approximator, being to model physical nonlinear phenomena and to solve complex inversion problems in a very short time (Krasnopolsky et al., 1995). Indeed, once the training phase is completed, it can be applied in a very fast manner to new data so that the computational burden required for the data processing is drastically reduced. This characteristic assumes an important role when considering its possible application to high-revisit time sensors like Meteosat Second Generation (MSG) Spin Enhanced Visible and Infrared Imager (SEVIRI). Indeed, the algorithms based on radiative transfer model simulations are generally time consuming, making its application in near-realtime difficult.

In the remote sensing of the atmosphere, neural networks (NNs) have been successfully applied in order to address different problems such as height resolved ozone retrievals (Del Frate et al., 2002; Müller et al., 2003), retrieval of temperature profiles (Churnside et al., 1994; Del Frate and Schiavon, 1999), cloud classification (Lee et al., 1990; Bankert, 1994), temperature estimations (Butler et al., 1996) and humidity profiles retrieval (Cabrera-Mercader and Staelin, 1995; Del Frate and Schiavon, 1999; Blackwell, 2005). Furthermore, Gardner and Dorling (1998) and Hsieh and Tang (1998) demonstrated how NNs can resolve inverse problems involving complex physical behaviors. It has to be underlined that when a new applicative scenario is considered, the correct and complete design of an NN algorithm is not trivial because, in order to obtain a satisfactory performance, various issues need to be appropriately taken into account; amongst
Table 2. Training, test and validation sets for the ash mass, $r_{\mathrm{eff}}$ and AOD retrievals.

\begin{tabular}{lrrrr}
\hline Date & TrS & TeS & VaS & Total \\
\hline 6 May 2010, 11:55 UTC & 22365 & 10166 & 8133 & 40664 \\
7 May 2010, 14:30 UTC & 14399 & 6545 & 5236 & 26180 \\
8 May 2010, 13:20 UTC & 17640 & 8018 & 6414 & 32072 \\
13 May 2010, 12:00 UTC & 25527 & 11603 & 9283 & 46413 \\
\hline Total & 79931 & 36332 & 29066 & \\
\hline
\end{tabular}

the most crucial ones, we note the definition of the input and the output vectors, the generation of the data set necessary for the training phase and the optimization of the network parameters. These tasks strongly depend on the specific retrieval problem and they need to be addressed and characterized carefully in order to avoid failures: due either to overfitting or to a scarce capability in the determination of the desired input-output relationship.

Recently, NNs were applied to a scenario for the detection of ash plume and the retrieval of the ash mass for the Etna volcano scenario, using a topology involving channels centered at $11 \mu \mathrm{m}$ and $12 \mu \mathrm{m}$, plus the water vapor absorption at $7.3 \mu \mathrm{m}$ (Picchiani et al., 2011). In such a study, the retrieval was only conducted above the sea, since the scenario did not imply the presence of ash and meteorological clouds on the same pixels. In this study, the procedure has been extended to completely characterize the set of $\mathrm{SO}_{2}$ and ash parameters over a more complex scenario such as the Eyjafjallajókull volcano. Different NNs have been used for retrieving ash total mass, particle effective radius $\left(r_{\text {eff }}\right)$, aerosol optical depth (AOD) at $11 \mu \mathrm{m}$ and $\mathrm{SO}_{2}$ at $8.7 \mu \mathrm{m}$ total column abundance from MODIS images. The adopted test case involves high meteorological cloud contamination, representing a very essential condition to run RTM-based approach (see Sect. 3.2 for details). In fact, to perform the retrieval of eruptive products, classical methods need to be tuned, especially to assess the characteristics of ashy pixels contaminated by meteorological clouds. This operational issue is overcome by the $\mathrm{NN}$ algorithm that, once trained, can be directly applied to the whole image without considering the presence of meteorological clouds. Since the performance of the neural network is closely related to the reliability of training samples used, the reference data set has been selected considering two different scenarios: volcanic clouds over the sea and volcanic clouds over meteorological clouds. For both cases it has adopted the same retrieval strategy, considering two different underlying surface temperatures that for the first case is the sea surface temperature and for the second case is the meteorological cloud-top temperature (Corradini et al., 2010).

The comparison between different input network topologies, also making use of the NN pruning as a feature selection technique, has been performed in order to find the most 

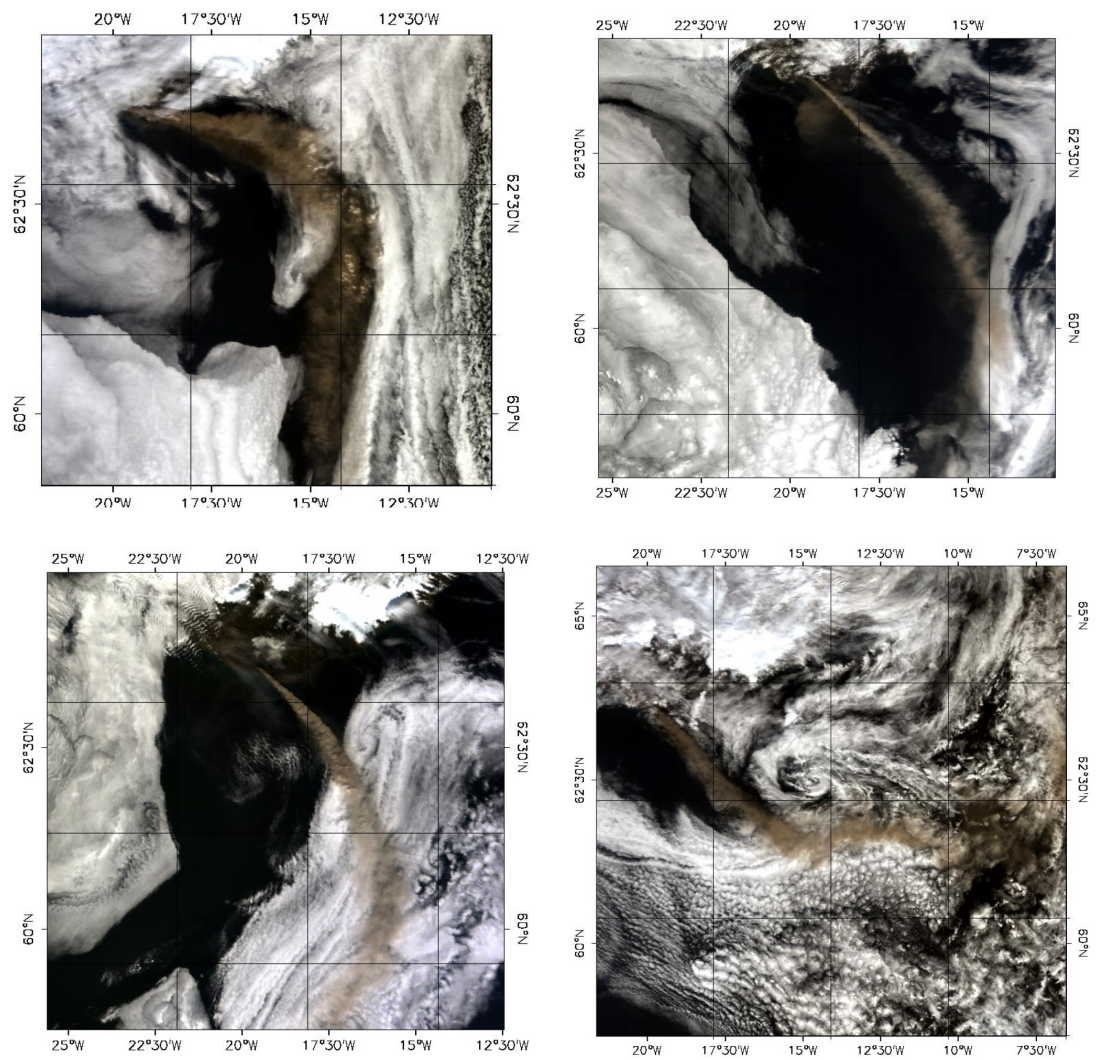

Figure 1. Training MODIS images RGB $(\mathrm{R}=\mathrm{ch} 1, \mathrm{G}=\mathrm{ch} 4, \mathrm{~B}=\mathrm{ch} 3)$, used in this study. Top panel, from left to right: 6 May 2010, 11:55 UTC; 7 May 2010, 14:30 UTC. Bottom panel, from left to right: 8 May 2010, 13:20 UTC; 13 May 2010, 12:00 UTC.
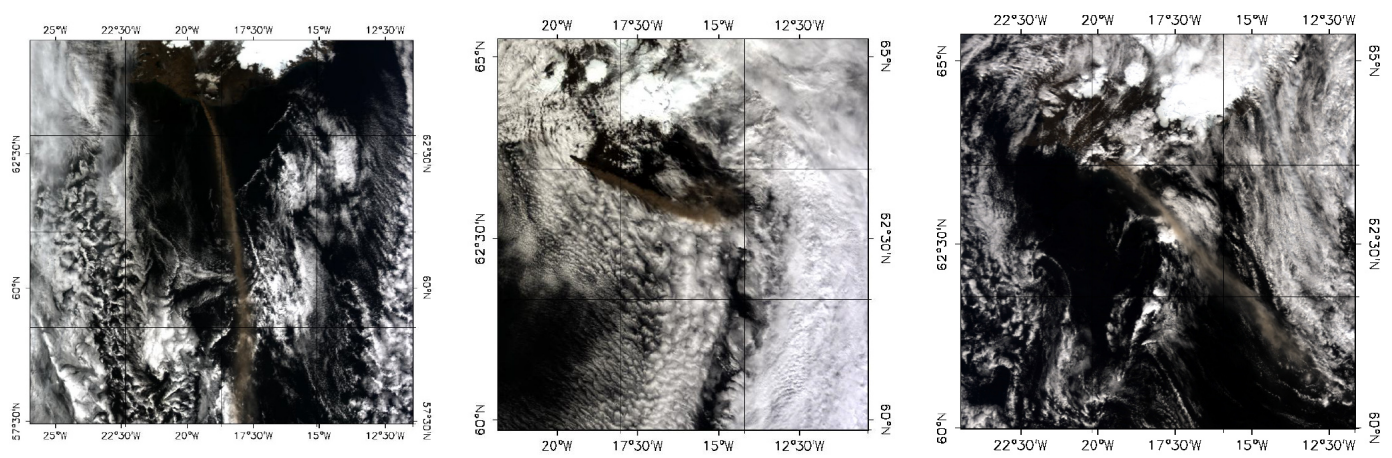

Figure 2. Validation MODIS images $\mathrm{RGB}(\mathrm{R}=\mathrm{ch} 1, \mathrm{G}=\mathrm{ch} 4, \mathrm{~B}=\mathrm{ch} 3)$, used in this study. From left to right: $11 \mathrm{May} 2010,14: 05 \mathrm{UTC}$; 12 May 2010, 12:55 UTC; 16 May 2010, 12:30 UTC.

significant inputs and increase the retrieval accuracy. Pruning techniques represent well-known methods generally used to avoid overfitting problems in training neural networks. Moreover, such approaches can also be used to select the most significant inputs for a specific problem (Del Frate et al., 2005). This feature's selection technique relies on the saliency concept, i.e., it analyzes the contribution of an input to the neurons activation and, in the end, to the performance of the network. In fact, one of the advantages of such an approach with respect to other non-parametric methods (such as ge- netic algorithms) using the training data as the unique source of information is that at the same time both the input feature set and the retrieval algorithm itself are optimized, the other techniques determine the best input combination with respect to a "fixed" inversion model (Pacifici et al., 2009). Moreover, some components may only be useful in the presence of other features, while being useless on their own. Such a possibility is effectively evaluated by the saliency computation, which generally takes into account all the parameters of the network simultaneously. To the best of our knowledge, this work rep- 

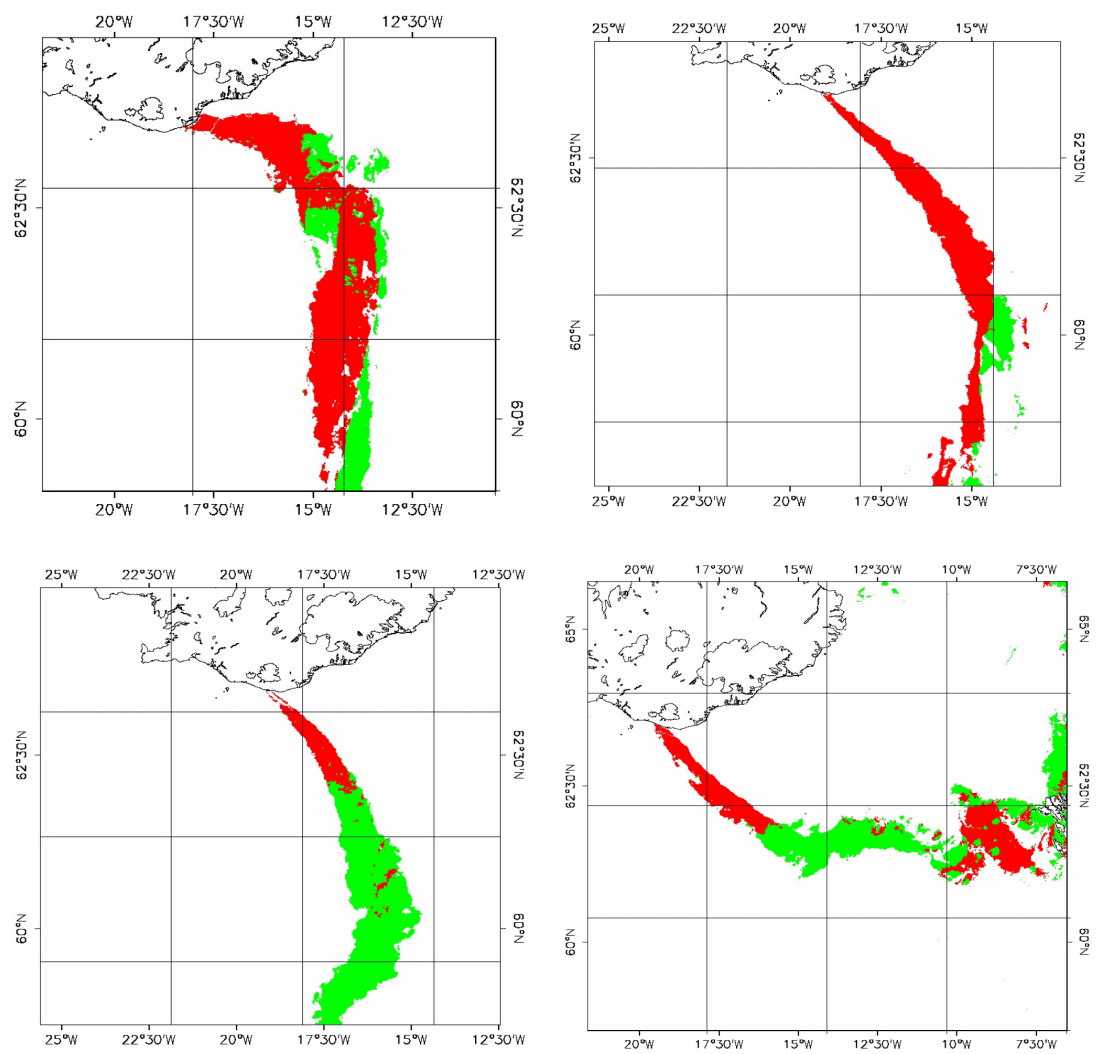

Figure 3. Ash detection maps of training data sets: 6 May 2010, 11:55 UTC (top left); 7 May 2010, 14:30 UTC (top right); 8 May 2010, 13:20 UTC (bottom left); 13 May 2010, 12:00 UTC (bottom right). Volcanic ash clouds over sea alone in red, ash clouds over meteorological clouds in green.
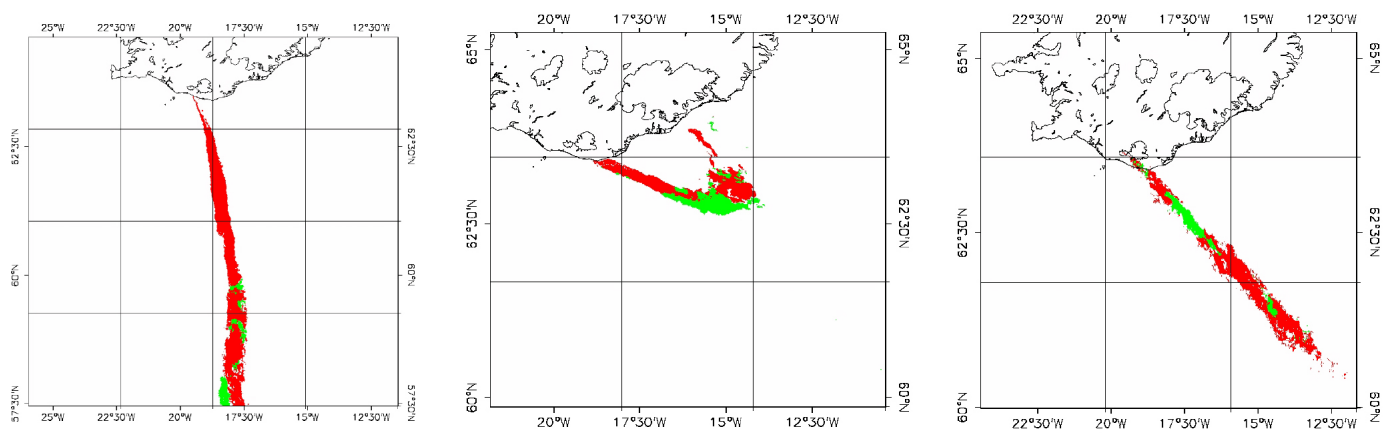

Figure 4. Ash detection maps of validation data sets: 11 May 2010, 14:05 UTC (left); 12 May 2010, 12:55 UTC (middle); 16 May 2010, 12:30 UTC (right). Volcanic ash clouds over sea alone in red, ash clouds over meteorological clouds in green.

resents the first attempt at using the NN pruning technique for the selection of most significant wavelengths in the visible-infrared range for ash parameters and $\mathrm{SO}_{2}$ retrieval.

The work is organized as follows. Firstly, we provide an overview of the considered scenario, discussing the MODIS sensor characteristics as well (Sect. 2), then we discuss the basic concepts of ash and $\mathrm{SO}_{2}$ parameters retrievals (Sect. 3). In Sect. 4, the NN approach is introduced while in Sect. 5 the methodology is described. Finally the results are discussed (Sect. 6) and then the conclusions are reported (Sect. 7).

\section{Test case description - the Eyjafjallajókull eruption}

Eyjafjallajökull volcano $\left(63.63^{\circ} \mathrm{N}, 19.62^{\circ} \mathrm{W}\right)$ is a $1666 \mathrm{~m}$ high stratovolcano with a $2.5 \mathrm{~km}$ wide summit caldera located in the south of Iceland. Although Eyjafjallajökull has been known to erupt throughout history, it has been less active than other volcanoes in Iceland's eastern volcanic zone (Smithsonian Institution, Global Volcanism Program). A significant eruption took place in 1821 and featured intermit- 

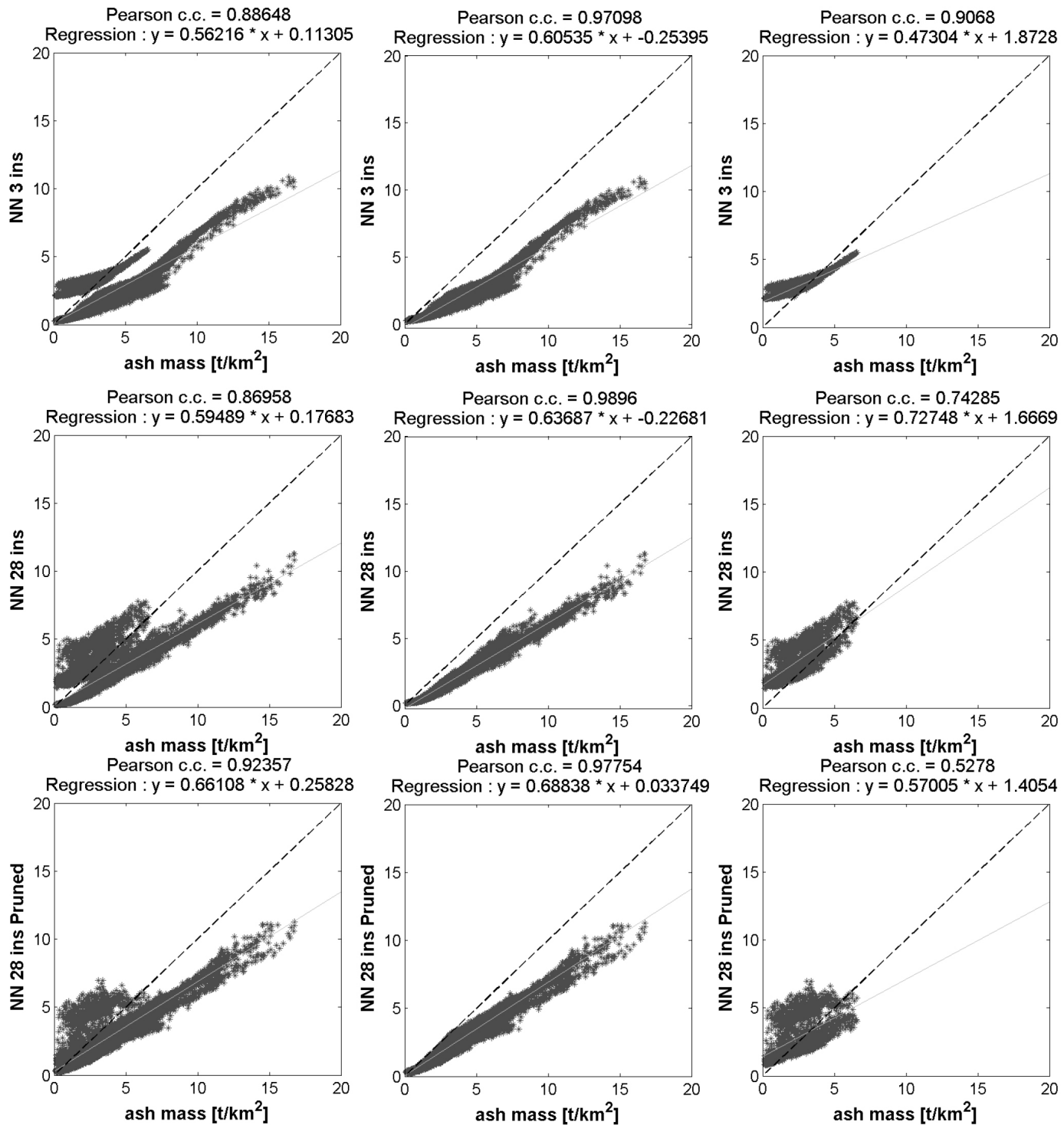

Figure 5. Scatterplots for ash mass networks, 3 inputs (top row), 28 inputs (middle row) and 28 inputs pruned (bottom row), applied to the validation set of 11 May 2010, 14:05 UTC, divided into total patterns (left column), patterns over sea (middle column) and patterns over meteorological clouds (right column).

Table 3. Training, test and validation sets for the $\mathrm{SO}_{2}$ retrievals.

\begin{tabular}{lrrrr}
\hline Date & TrS & TeS & VaS & Total \\
\hline 6 May 2010, 11:55 UTC & 13591 & 6178 & 4941 & 24710 \\
7 May 2010, 14:30 UTC & 10026 & 4557 & 3646 & 18229 \\
8 May 2010, 13:20 UTC & 7036 & 3198 & 2559 & 5172 \\
13 May 2010, 12:00 UTC & 21471 & 9760 & 7807 & 39038 \\
\hline Total & 51124 & 17693 & 18953 & \\
\hline
\end{tabular}

Table 4. Independent validation sets for ash parameters divided considering the volcanic cloud over sea and volcanic cloud over meteorological clouds.

\begin{tabular}{lrrr}
\hline Date & VaS (Total) & VaS (Sea) & VaS (Clouds) \\
\hline 11 May 2010, 14:05 UTC & 19640 & 17264 & 2376 \\
12 May 2010, 12:55 UTC & 8187 & 5095 & 3092 \\
16 May 2010, 12:30 UTC & 9418 & 7545 & 1873 \\
\hline
\end{tabular}



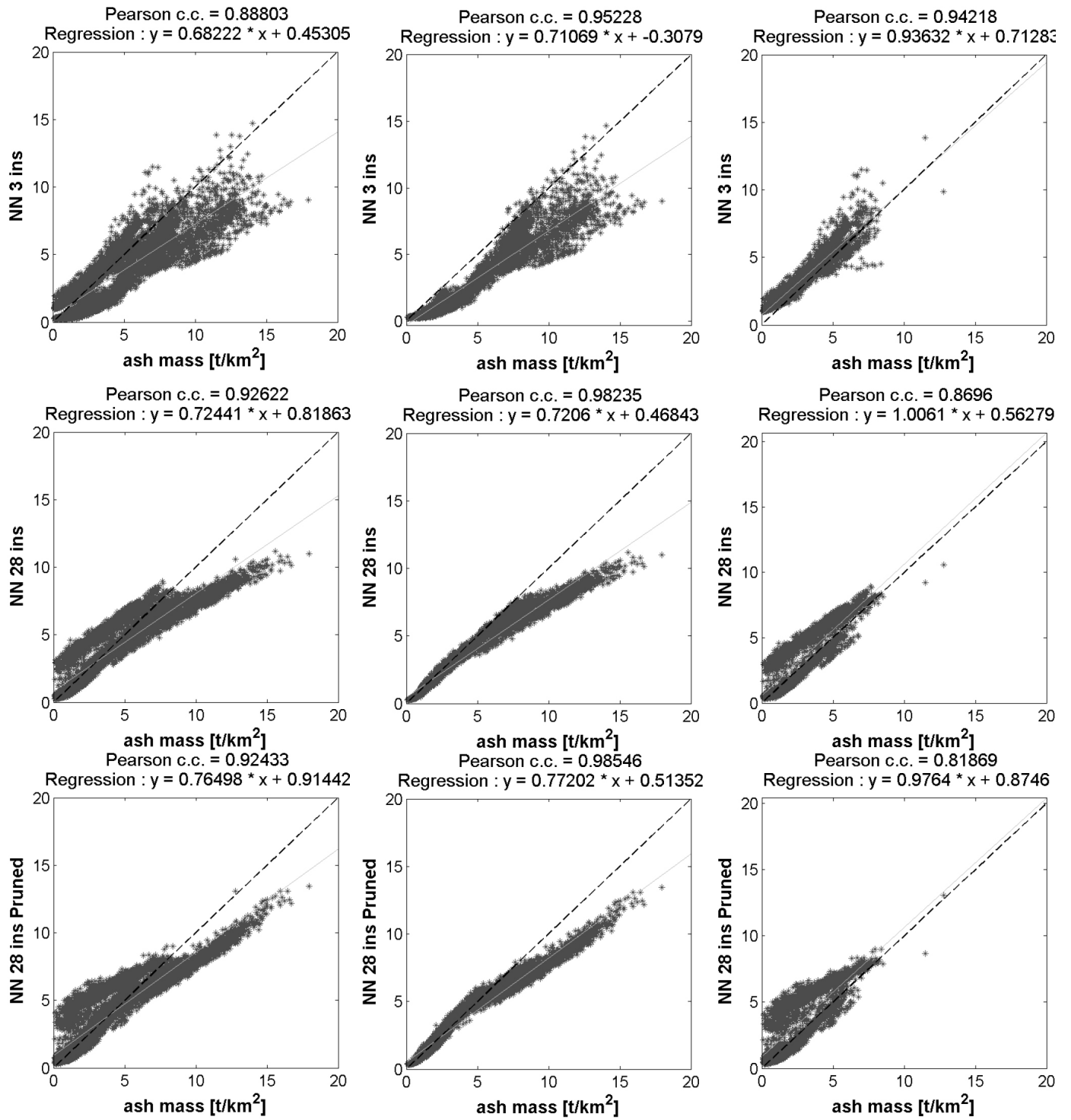

Figure 6. Scatterplots for ash mass networks, 3 inputs (top row), 28 inputs (middle row) and 28 inputs pruned (bottom) row, applied to the validation set of 12 May 2010, 12:55 UTC, divided into total patterns (left column), patterns over sea (middle column) and patterns over meteorological clouds (right column).

Table 5. Independent $\mathrm{SO}_{2}$ validation sets divided into clouds over sea and clouds over meteorological clouds.

\begin{tabular}{lrrr}
\hline Date & VaS (Total) & VaS (Sea) & VaS (Clouds) \\
\hline 11 May 2010, 14:05 UTC & 13952 & 13754 & 198 \\
12 May 2010, 12:55 UTC & 6211 & 4343 & 1868 \\
16 May 2010, 12:30 UTC & 10429 & 8210 & 2219 \\
\hline
\end{tabular}

tent explosive events that deposited a thin tephra layer on the flanks of the volcano over a period of about 18 months.

The explosive activity occurring from 14 April to 23 May 2010 caused widespread disruption to aviation, with an enor- mous impact on the world economy. This eruption may be considered the biggest explosive eruption in Iceland since that of Hekla in 1947 (Zehner, 2010).

Following an intense seismic swarm, the eruption began from the summit of the Eyjafjallajókull volcano at 01:15 UTC on 14 April 2010. Initially the activity was subglacial, but around 06:00 UTC a white (steam-rich) eruption plume rose from the summit (Sigmundsson et al., 2010).

Three different eruption phases were observed (Zenher, 2010):

- a sustained phreatomagmatic eruption occurred from 14 to 17 April with the production of a large amount of fine ash of trachyandesite composition with a $5-9 \mathrm{~km}$ 
Table 6. RMSE values related to ash parameters and $\mathrm{SO}_{2}$ for the independent validation sets. The inputs for the ash parameters are the MODIS channels 28, 31 and 32, while for the $\mathrm{SO}_{2}$, the MODIS channels 29, 31 and 32.

\begin{tabular}{|c|c|c|c|c|c|c|c|c|c|}
\hline \multirow[t]{2}{*}{3 input NN } & \multicolumn{3}{|c|}{11 May 2010} & \multicolumn{3}{|c|}{12 May 2010} & \multicolumn{3}{|c|}{16 Маy 2010} \\
\hline & $\begin{array}{r}\text { Total } \\
\text { (SD / RMSE) }\end{array}$ & $\begin{array}{r}\text { Sea } \\
(\mathrm{SD} / \mathrm{RMSE})\end{array}$ & $\begin{array}{r}\text { Clouds } \\
\text { (SD / RMSE) }\end{array}$ & $\begin{array}{r}\text { Total } \\
(\mathrm{SD} / \mathrm{RMSE})\end{array}$ & $\begin{array}{r}\text { Sea } \\
(\mathrm{SD} / \mathrm{RMSE})\end{array}$ & $\begin{array}{r}\text { Clouds } \\
\text { (SD / RMSE) }\end{array}$ & $\begin{array}{r}\text { Total } \\
(\mathrm{SD} / \mathrm{RMSE})\end{array}$ & $\begin{array}{r}\text { Sea } \\
(\mathrm{SD} / \mathrm{RMSE})\end{array}$ & $\begin{array}{r}\text { Clouds } \\
\text { (SD / RMSE) }\end{array}$ \\
\hline Ash re & $1.44 / 1.01$ & $1.31 / 1.02$ & $1.30 / 0.88$ & $1.54 / 1.38$ & $1.60 / 1.41$ & $1.43 / 1.32$ & $1.85 / 1.80$ & $1.67 / 1.68$ & $1.21 / 2.22$ \\
\hline Ash AOD & $0.27 / 0.22$ & $0.27 / 0.23$ & $0.14 / 0.09$ & $0.47 / 0.14$ & $0.39 / 0.13$ & $0.26 / 0.15$ & $0.49 / 0.51$ & $0.46 / 0.41$ & $0.48 / 0.80$ \\
\hline $\mathrm{SO}_{2}$ & $1.61 / 1.16$ & $1.61 / 1.15$ & $0.56 / 1.48$ & $2.03 / 1.24$ & $2.19 / 0.79$ & $1.16 / 1.16$ & $2.60 / 3.74$ & $2.60 / 3.94$ & $2.60 / 2.89$ \\
\hline
\end{tabular}

Table 7. RMSE values related to ash parameters and $\mathrm{SO}_{2}$ for the independent validation sets.

\begin{tabular}{|c|c|c|c|c|c|c|c|c|c|}
\hline \multirow[t]{2}{*}{28 input NN } & \multicolumn{3}{|c|}{11 May 2010} & \multicolumn{3}{|c|}{12 May 2010} & \multicolumn{3}{|c|}{16 May 2010} \\
\hline & $\begin{array}{r}\text { Total } \\
\text { (SD / RMSE) }\end{array}$ & $\begin{array}{r}\text { Sea } \\
(\mathrm{SD} / \mathrm{RMSE})\end{array}$ & $\begin{array}{r}\text { Clouds } \\
(\mathrm{SD} / \mathrm{RMSE})\end{array}$ & $\begin{array}{r}\text { Total } \\
(\mathrm{SD} / \mathrm{RMSE})\end{array}$ & $\begin{array}{r}\text { Sea } \\
(\mathrm{SD} / \mathrm{RMSE})\end{array}$ & $\begin{array}{r}\text { Clouds } \\
(\mathrm{SD} / \mathrm{RMSE})\end{array}$ & $\begin{array}{r}\text { Total } \\
(\mathrm{SD} / \mathrm{RMSE})\end{array}$ & $\begin{array}{r}\text { Sea } \\
(\mathrm{SD} / \mathrm{RMSE})\end{array}$ & $\begin{array}{r}\text { Clouds } \\
\text { (SD / RMSE) }\end{array}$ \\
\hline Ash re & $1.44 / 0.84$ & $1.31 / 0.39$ & $1.30 / 2.17$ & $1.54 / 0.73$ & $1.60 / 0.24$ & $1.43 / 1.15$ & $1.85 / 0.82$ & $1.67 / 0.70$ & $1.21 / 1.18$ \\
\hline Ash AOD & $0.27 / 0.13$ & $0.27 / 0.11$ & $0.14 / 0.24$ & $0.35 / 0.16$ & $0.39 / 0.16$ & $0.26 / 0.15$ & $0.49 / 0.23$ & $0.46 / 0.20$ & $0.48 / 0.33$ \\
\hline $\mathrm{SO}_{2}$ & $1.61 / 1.38$ & $1.61 / 1.34$ & $0.56 / 3.09$ & $2.03 / 1.37$ & $2.19 / 0.75$ & $1.16 / 2.22$ & $2.60 / 1.82$ & $2.60 / 1.20$ & $2.60 / 3.2$ \\
\hline
\end{tabular}

Table 8. RMSE values related to ash parameters and $\mathrm{SO}_{2}$ for the independent validation sets.

\begin{tabular}{|c|c|c|c|c|c|c|c|c|c|}
\hline \multirow[t]{2}{*}{ Pruned NN } & \multicolumn{3}{|c|}{11 May 2010} & \multicolumn{3}{|c|}{12 May 2010} & \multicolumn{3}{|c|}{16 May 2010} \\
\hline & $\begin{array}{r}\text { Total } \\
\text { (SD / RMSE) }\end{array}$ & $\begin{array}{r}\text { Sea } \\
(\mathrm{SD} / \mathrm{RMSE})\end{array}$ & $\begin{array}{r}\text { Clouds } \\
(\mathrm{SD} / \mathrm{RMSE})\end{array}$ & $\begin{array}{r}\text { Total } \\
\text { (SD / RMSE) }\end{array}$ & $\begin{array}{r}\text { Sea } \\
(\mathrm{SD} / \mathrm{RMSE})\end{array}$ & $\begin{array}{r}\text { Clouds } \\
(\mathrm{SD} / \mathrm{RMSE})\end{array}$ & $\begin{array}{r}\text { Total } \\
(\mathrm{SD} / \mathrm{RMSE})\end{array}$ & $\begin{array}{r}\text { Sea } \\
(\mathrm{SD} / \mathrm{RMSE})\end{array}$ & $\begin{array}{r}\text { Clouds } \\
\text { (SD / RMSE) }\end{array}$ \\
\hline Ash re & $1.44 / 0.91$ & $1.31 / 0.66$ & $1.30 / 1.94$ & $1.54 / 0.83$ & $1.60 / 0.39$ & $1.43 / 1.25$ & $1.85 / 0.83$ & $1.67 / 0.75$ & $1.21 / 1.10$ \\
\hline Ash AOD & $0.35 / 0.18$ & $0.35 / 0.18$ & $0.19 / 0.15$ & $0.47 / 0.20$ & $0.51 / 0.20$ & $0.34 / 0.19$ & $0.49 / 0.3$ & $0.46 / 0.25$ & $0.48 / 0.40$ \\
\hline $\mathrm{SO}_{2}$ & $1.61 / 1.42$ & $1.61 / 1.31$ & $0.56 / 4.88$ & $2.03 / 2.00$ & $2.19 / 1.19$ & $1.16 / 3.17$ & $2.60 / 2.04$ & $2.60 / 0.95$ & $2.60 / 4.03$ \\
\hline
\end{tabular}

high volcanic ash (Gudmundsson et al., 2010). Prevailing winds carried the ash-rich eruption plume towards the southeast and south and thereafter over Europe;

- from 18 April to 4 May, a marked change in type and intensity of the eruption was registered although the composition of the erupted magma was unchanged. The eruption type changed from phreatomagmatic to magmatic, implying that external water had no longer ready access to the vents. During this phase, the explosive activity decreased by an order of magnitude compared to the previous phreatomagmatic one, with a reduction of ash emission with a plume height of between 2 and $5 \mathrm{~km}$ a.s.1.;

- from 5 to 23 May, the eruption type changed to explosive. Following an episode of renewed seismic activity, the Eyjafjallajókull volcano changed phases, with a return to the previous magmatic phases with greater ash production. The intensity of explosive activity increased again and observations reported volcanic ash heights at around $4-6 \mathrm{~km}$, sometimes reaching up to $8-9 \mathrm{~km}$. This resurgence in activity led to further disruption of air traffic in Europe.
In this work, we have concentrated our attention on the last eruption phase, by considering seven MODIS images collected between 6 and 16 May 2010.

MODIS is a multi-spectral instrument aboard the Earth Observing System (EOS) Terra and Aqua satellites (Barnes et al., 1998; http://modis.gsfc.nasa.gov/). These two satellites have different equatorial crossing times: Terra is characterized by a morning overpass, while Aqua by an afternoon one, with global coverage in 1 or 2 days. MODIS covers 36 spectral bands, from visible (VIS) to thermal infrared (TIR), and a spatial resolution that varies from $250 \mathrm{~m}$ to $1000 \mathrm{~m}$, depending on the acquisition mode.

\section{Ash and $\mathrm{SO}_{2}$ retrievals}

In this section, the standard ash and $\mathrm{SO}_{2}$ retrieval procedures applied to the MODIS measurements in the TIR will be briefly described. The TIR channels' characteristics are given in Table 1. The products obtained have been used as target output for NN training and as "truth" in the validation phases. 

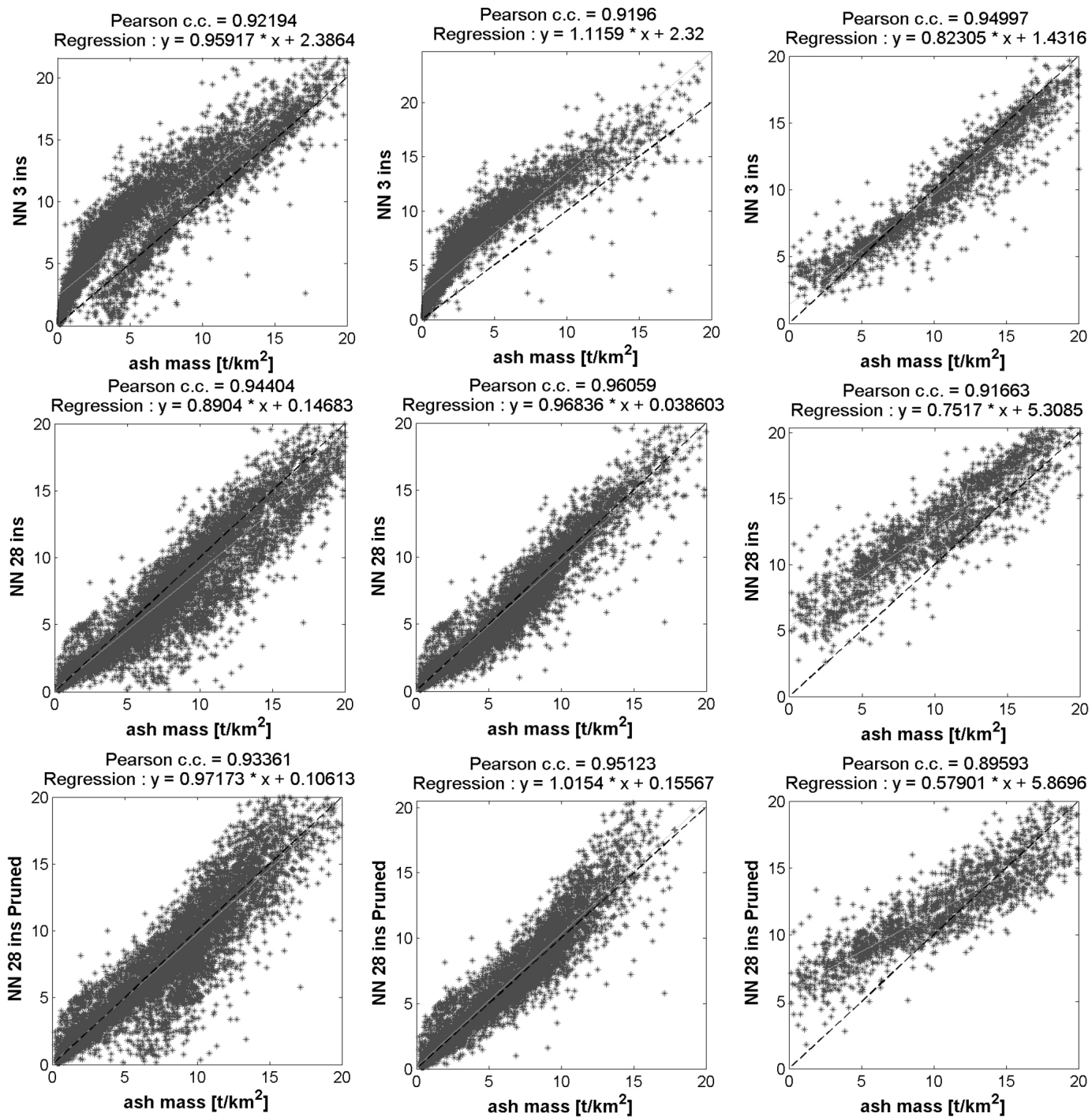

Figure 7. Scatterplots for ash mass networks, 3 inputs (top row), 28 inputs (middle row) and 28 inputs pruned (bottom) row, applied to the validation set of 16 May 2010, 12:30 UTC, divided into total patterns (left column), patterns over sea (middle column) and patterns over meteorological clouds (right column).

\subsection{Ash detection and retrievals}

The most widely adopted approach for the detection of volcanic ash, and to discriminate it from meteorological clouds, is based on the different spectral absorption of ash and water vapor/ice particles between 11-12 $\mu \mathrm{m}$. The difference between the brightness temperature (BTD) computed from the two channels centered around $11\left(T_{\mathrm{b}, 11}\right)$ and $12 \mu \mathrm{m}\left(T_{\mathrm{b}, 12}\right)$ is generally negative for volcanic ash and positive for meteorological clouds (Prata, 1989a). The ash $r_{\text {eff }}$ and AOD are retrieved by computing the inverted arches curves BTD$T_{\mathrm{b}, 11}$ using radiative transfer models, whilst the ash mass is estimated using the simplified formula introduced by Wen and Rose in 1994 (Wen and Rose, 1994; Yu et al., 2002). The BTD method has been applied to satellite instruments as the Advanced Very High Resolution Radiometer (AVHRR) (Prata, 1989b; Wen and Rose, 1994; Corradini et al., 2010), MODIS (Hillger et al., 2002; Watson et al., 2004; Tupper at al., 2004; Corradini et al., 2008, 2010, 2011), the Geostationary Operational Environmental Satellite (GOES) (Yu et al., 2002) and the Spin Enhanced Visible and Infrared Imager (SEVIRI) measurements (Prata and Kerkmann, 2007; Corradini et al., 2009).

The simulated top-of-the-atmosphere (TOA) radiances look-up tables (LUT) necessary for the retrievals are computed using the MODTRAN (MODerate resolution atmospheric TRANsmission) 4 (Berk et al., 1989; Anderson et al., 1995) radiative transfer model (RTM) (Corradini et al., 2009, 2010, 2011) using the Keflavíkurflugvöllur (63.95 N, 

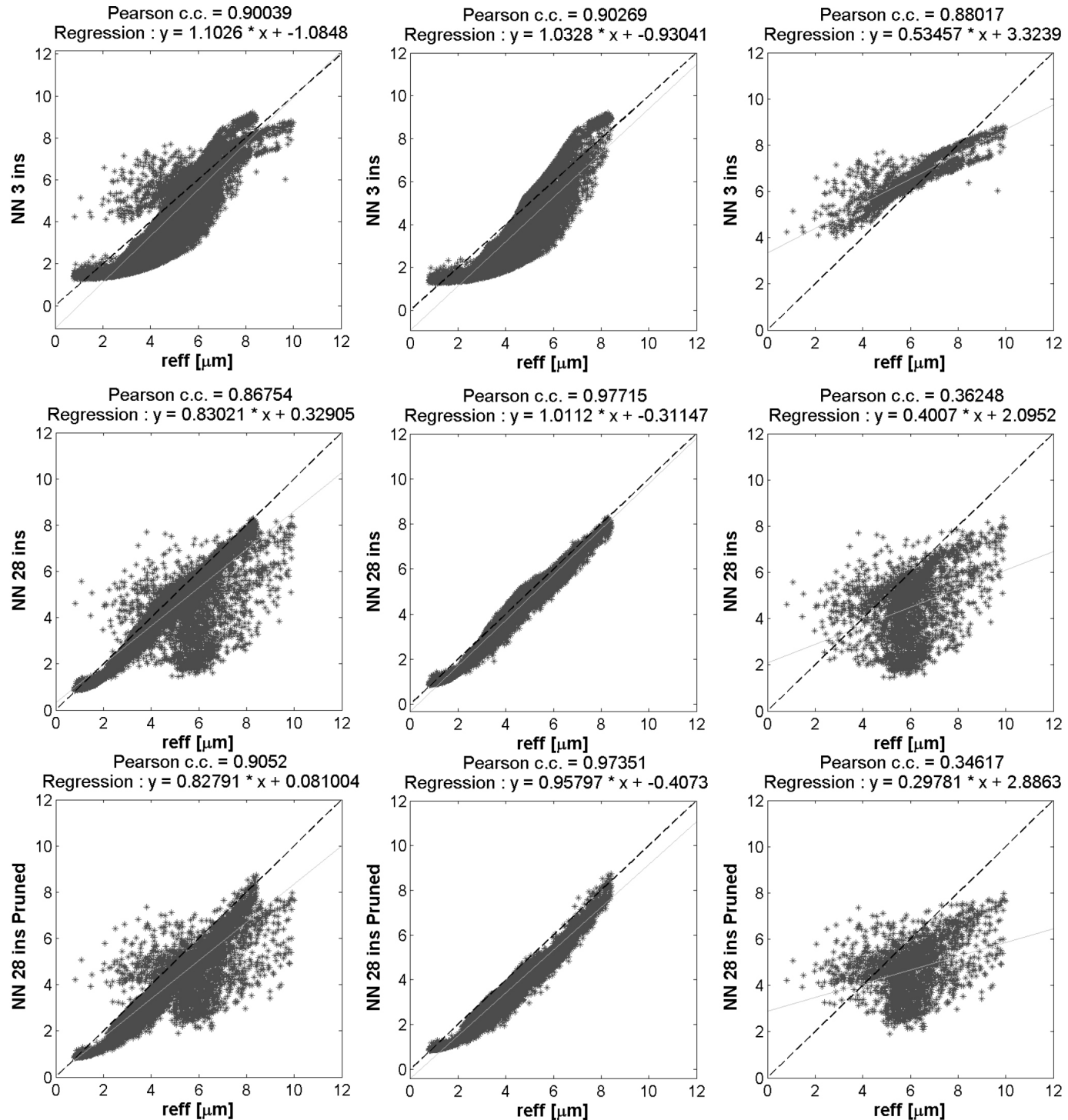

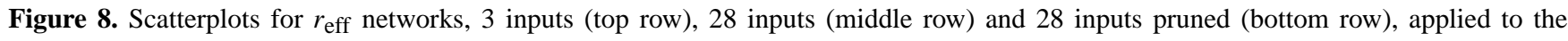
validation set of 11 May 2010, 14:05 UTC, divided into total patterns (left column), patterns over sea (middle column) and patterns over meteorological clouds (right column).

$\left.22.60^{\circ} \mathrm{W}\right) \mathrm{WMO}$ atmospheric profiles $(\mathrm{PTH})$ and andesitic ash optical properties (Pollack, 1973).

\section{2 $\mathrm{SO}_{2}$ retrieval}

The $\mathrm{SO}_{2}$ retrieval in the TIR spectral range is realized by exploiting its wide absorption around $8.7 \mu \mathrm{m}$ (MODIS channel 29). The retrieval scheme derived from Realmuto et al. $(1994,1997)$ was initially applied to the Thermal Infrared Multispectral Scanner (TIMS) measurements, and later on was successfully extended to several space-based sensors such as MODIS (Watson et al., 2004; Corradini et al., 2009, 2010), Advanced Spaceborne Thermal Emission and Reflection Radiometer (ASTER) (Corradini et al., 2003; Pugnaghi et al., 2006) and SEVIRI (Corradini et al., 2009). The algorithm is based on a weighted least square fit procedure between the simulated radiances obtained by varying the $\mathrm{SO}_{2}$ columnar amount with MODTRAN RTM and the sensor radiances measured. The $8.7 \mu \mathrm{m}$ band lies in the thermal infrared atmospheric window which is relatively transparent to water vapor and therefore generally used for the tropospheric volcanic clouds retrievals. Limitations to the applicability of this retrieval scheme are due to a lower thermal contrast between the $\mathrm{SO}_{2}$ cloud and the underlying surface, and opaque pixels, i.e., pixels where the minimum simulated radiance exceeds the TOA radiance measured by the sensor. A relevant improvement has been proposed by Corradini et al. (2009) to take into account the interference due to the ash presence 

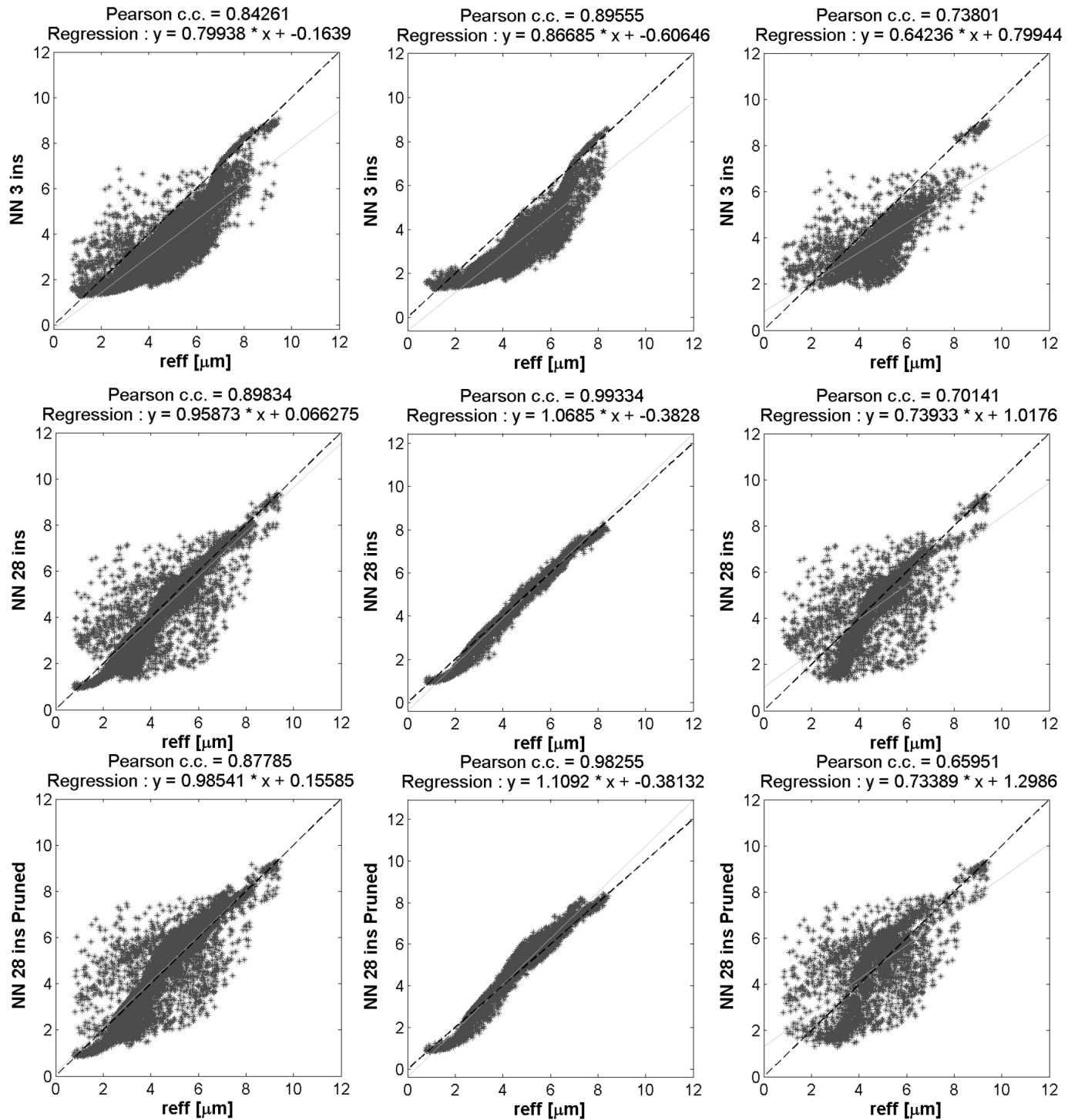

Figure 9. Scatterplots for $r_{\text {eff }}$ networks, 3 inputs (top row), 28 inputs (middle row) and 28 inputs pruned (bottom row), applied to the validation set of 12 May 2010, 12:55 UTC, divided into total patterns (left column), patterns over sea (middle column) and patterns over meteorological clouds (right column).

in the volcanic plume. Since ash and $\mathrm{SO}_{2}$ are often ejected simultaneously during volcanic eruptions and volcanic ash absorbs in the same $8.7 \mu \mathrm{m}$ band, the $\mathrm{SO}_{2}$ abundance can be highly overestimated if the ash contribution to the TOA radiance is neglected. The ash correction on $\mathrm{SO}_{2}$ retrieval has been recently validated by comparing the $\mathrm{SO}_{2}$ flux extract from a MODIS image and the flux measured by the FLux Automatic MEasurements (FLAME) ground-based network (Salerno et al., 2009) deployed at Mt. Etna, Sicily (Merucci et al., 2011). The $\mathrm{SO}_{2}$ maps presented here are corrected for the ash cloud content and have been retrieved by means of custom procedures described in detail in Corradini et al. (2009). Amongst the different sources of ash and $\mathrm{SO}_{2}$ retrieval errors deriving from the uncertainties on RTM input parame- ters (Corradini et al., 2008, 2009), the non-uniformity of the surface underlying the volcanic cloud is one of the most critical. Such a condition is common when the volcanic cloud is wide enough to exist in a region in which a partial meteorological cloud cover is present. In these cases the retrievals have to be realized by considering different surface temperatures for the different volcanic cloud parts existing over different surfaces (land, sea or meteorological clouds). For the case study considered in this work, the surfaces under the volcanic cloud are sea and meteorological clouds (see Figs. 1 and 2). The sea surface temperature is computed by the inversion of the radiative transfer equation in the TIR spectral range (Corradini et al., 2008), while the surface temperature of the meteorological clouds is estimated by computing the 
Table 9. MODIS channels selected by the input pruning.

\begin{tabular}{|c|c|c|c|c|c|}
\hline \multirow{2}{*}{$\begin{array}{l}\text { MODIS } \\
\text { channels }\end{array}$} & \multirow{2}{*}{$\begin{array}{l}\text { Central } \\
\text { wavelength }[\mu \mathrm{m}]\end{array}$} & \multicolumn{4}{|c|}{ Parameters } \\
\hline & & Ash mass & $r_{\text {eff }}$ & AOD & $\mathrm{SO}_{2}$ \\
\hline 1 & 0.645 & X & X & X & \\
\hline 2 & 0.858 & & $X$ & $\mathrm{X}$ & \\
\hline 3 & 0.469 & X & $\mathrm{X}$ & $\mathrm{X}$ & $X$ \\
\hline 4 & 0.555 & $X$ & $X$ & $X$ & $\mathrm{X}$ \\
\hline 5 & 1.240 & $X$ & & & \\
\hline 6 & 1.640 & $X$ & & & $X$ \\
\hline 7 & 2.130 & $X$ & X & & \\
\hline 8 & 0.421 & $X$ & $X$ & $X$ & $X$ \\
\hline 17 & 0.905 & & $X$ & $X$ & \\
\hline 18 & 0.936 & $X$ & $X$ & & \\
\hline 19 & 0.940 & $X$ & $X$ & & \\
\hline 20 & 3.750 & $X$ & $X$ & & \\
\hline 21 & 3.959 & & & & \\
\hline 22 & 3.959 & & & & $X$ \\
\hline 23 & 4.050 & X & X & X & $X$ \\
\hline 24 & 4.465 & & & & \\
\hline 25 & 4.515 & $X$ & $X$ & $X$ & \\
\hline 26 & 1.375 & $\mathrm{X}$ & $X$ & & $X$ \\
\hline 27 & 6.715 & & & & \\
\hline 28 & 7.325 & & & & \\
\hline 29 & 8.550 & $X$ & & $X$ & $X$ \\
\hline 30 & 9.730 & & & & \\
\hline 31 & 11.03 & $X$ & $X$ & $X$ & $X$ \\
\hline 32 & 12.02 & $\mathrm{X}$ & $\mathrm{X}$ & $X$ & \\
\hline 33 & 13.335 & & & & \\
\hline 34 & 13.635 & & & & \\
\hline 35 & 13.935 & & $X$ & & \\
\hline 36 & 14.235 & $X$ & $X$ & $X$ & $X$ \\
\hline Total & & 17 & 17 & 12 & 10 \\
\hline
\end{tabular}

brightness temperature at $11 \mu \mathrm{m}$ (MODIS channel 31). This latter approximation is all the more valid for high and opaque meteorological clouds. In this case, the retrieval accuracy is lower than the one that can be achieved by considering a volcanic cloud over a sea surface due to the lower thermal contrast between meteorological cloud-top surface and ash cloud temperature (Watson et al., 2004).

In this work, the ash parameters and $\mathrm{SO}_{2}$ retrievals estimated with the methodology described in Corradini et al. $(2009,2010)$ have been used for NN training and validation.

\section{Neural networks}

Since the 1990s, NNs have been applied in many remote sensing fields (Atkinson and Tatnall, 1997; Mas and Flores, 2008) including in significant atmospheric investigations (Gardner and Dorling, 1998). The increased interest in the management of remote sensing data with this technique can be understood considering the universal approximation property of the most common type of NN, the multi-layer percep- tron (MLP). The theorem, proven by Cybenko (1989), explains that an MLP with a single hidden layer, which contains a finite number of neurons with sigmoidal activation functions, is a universal approximator among continuous functions on compact subsets of $R^{n}$. Additional benefits are the independence from a priori assumptions about the statistical characterization of the data and the possibility of easily incorporating different types of data (Foody, 1995). For these reasons, NNs have often been successfully used for the solution of the inverse problem of geophysical quantities from satellite measurements (Blackwell, 2005; Picchiani et al., 2011, 2012).

The architecture of an MLP is based on a simple processing unit, called a neuron, which collects the quantities presented in input through weighted connections, and produces the output applying an activation function to the weighted sum of the inputs. The neurons are interconnected and organized in at least three layers, one input layer, a variable number of intermediate hidden layers and one output layer. The first layer distributes the data, without processing them, to all neurons in the first hidden layer; then the information is passed to the second hidden layer and so on up to the output layer.

For remote sensing applications, usually, the input layer collects data values (the spectral signature of the respective pixel of the image) such as radiances or brightness temperatures from different spectral bands, with the number of nodes equal to the number of bands; meanwhile, the output layer provides the corresponding retrieved geophysical parameter value. In this work, we used the same approach developed in Picchiani et al. (2011) to train the NNs. The backpropagation algorithm (Bishop, 1995) has been applied performing a cross-validation approach (Haykin, 1994; Bishop, 1995) to avoid the possibility of over training, i.e., the memorization of specific patterns instead of statistical mapping linking the inputs to outputs and, therefore, hampering the generalization capability for new data. The back-propagation algorithm adopted featured re-scaled sigmoidal activation functions in each node, where a $[-1,+1]$ output range tends to be more convenient for neural networks.

Training with cross validation was carried out by splitting the training data into three sets: a training set, a cross validation set and a test set. These consisted respectively of $55 \%$, $25 \%$ and $20 \%$ of the total number of training samples (Tables 2 and 3). The first set was used for network training. The cross validation set, consisting of $25 \%$, was analyzed at a predefined number of epochs, to assess performance on data sets other than the training one. Finally, the test set $(20 \%)$ was used as an independent data source in order to assess network performance after the training phase. Since the NN performance is dependent on the data used in the training phase, the statistical representativeness of this latter must be considered. Many different settings influence the ability of an NN to generalize. Among the most important ones are the network topology (i.e., the number of hidden layers and neu- 

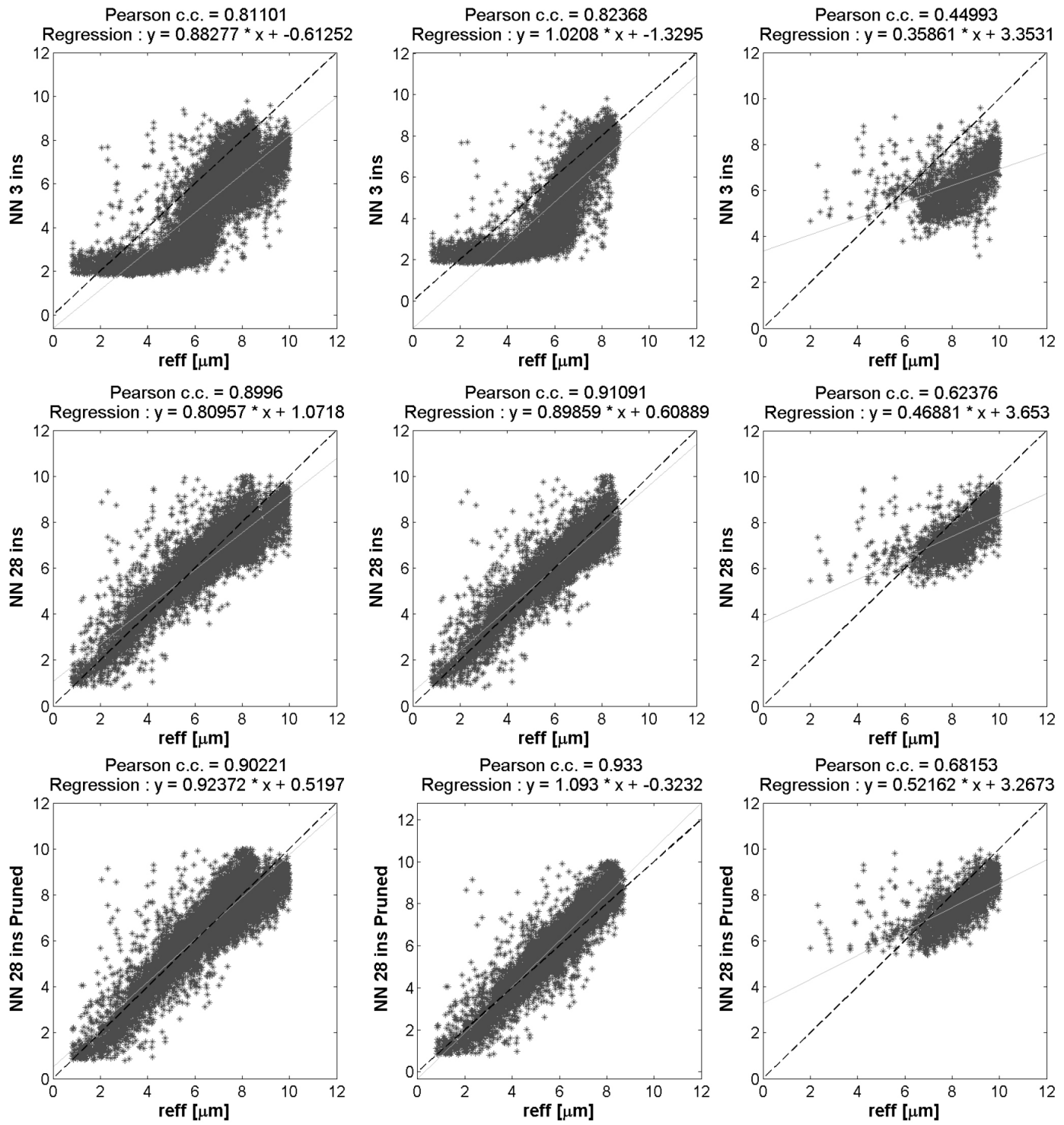

Figure 10. Scatterplots for $r_{\text {eff }}$ networks, 3 inputs (top row), 28 inputs (middle row) and 28 inputs pruned (bottom row), applied to the validation set of 16 May 2010, 12:30 UTC, divided into total patterns (left column), patterns over sea (middle column) and patterns over meteorological clouds (right column).

rons in each layer), the number of training epochs and the number of inputs. Concerning the latter aspects, a feature selection approach, aimed at selecting a subset of the inputs relevant for a given retrieval problem, could be very effective in this framework. Its two main purposes are to speed up the learning process, since the amount of data to be processed is reduced, and to give the possibility of empirically discovering the most effective spectral wavelengths for the particular retrieval problem.

A well-known feature selection technique using NNs is pruning, which is generally implemented by training a network larger than necessary and then by pruning the neurons and the connections that are not needed, i.e., the elements showing low influence on the network's result. In this way, the inputs node may also be pruned, so that the algorithm acts as a features selector (Pacifici et al., 2009), searching for wavelengths with major correlations with the geophysical parameters in output. After the training phase, the units (the network neurons) are analyzed to determine those not contributing significantly to the solution. This phase is the most important one in the procedure implementation, and it guides the connections suppression. The relative importance, or saliency, of different weights is the measurement, generally adopted to judge if a node will be removed. This is defined as the sum of weights afferent to the neuron, i.e., less important weights have smaller saliencies. 

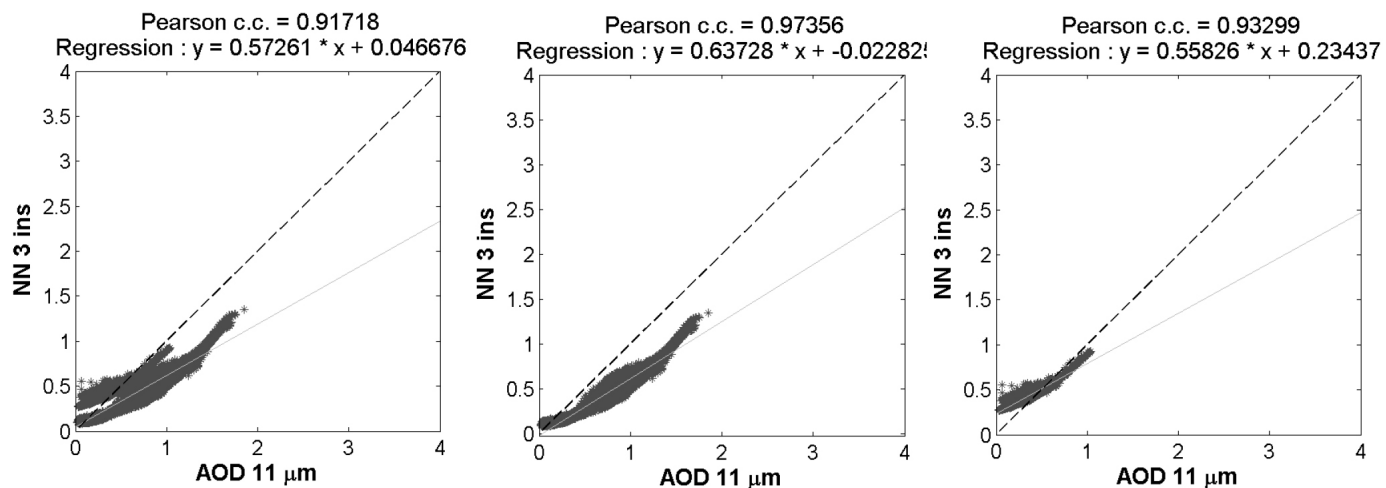

Pearson c.c. $=0.88935$

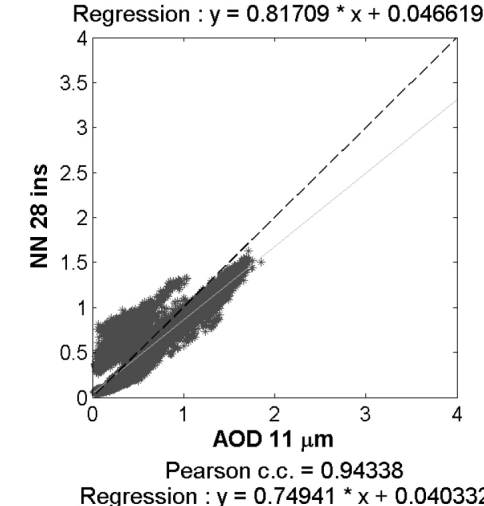

Pearson c.c. $=0.97359$
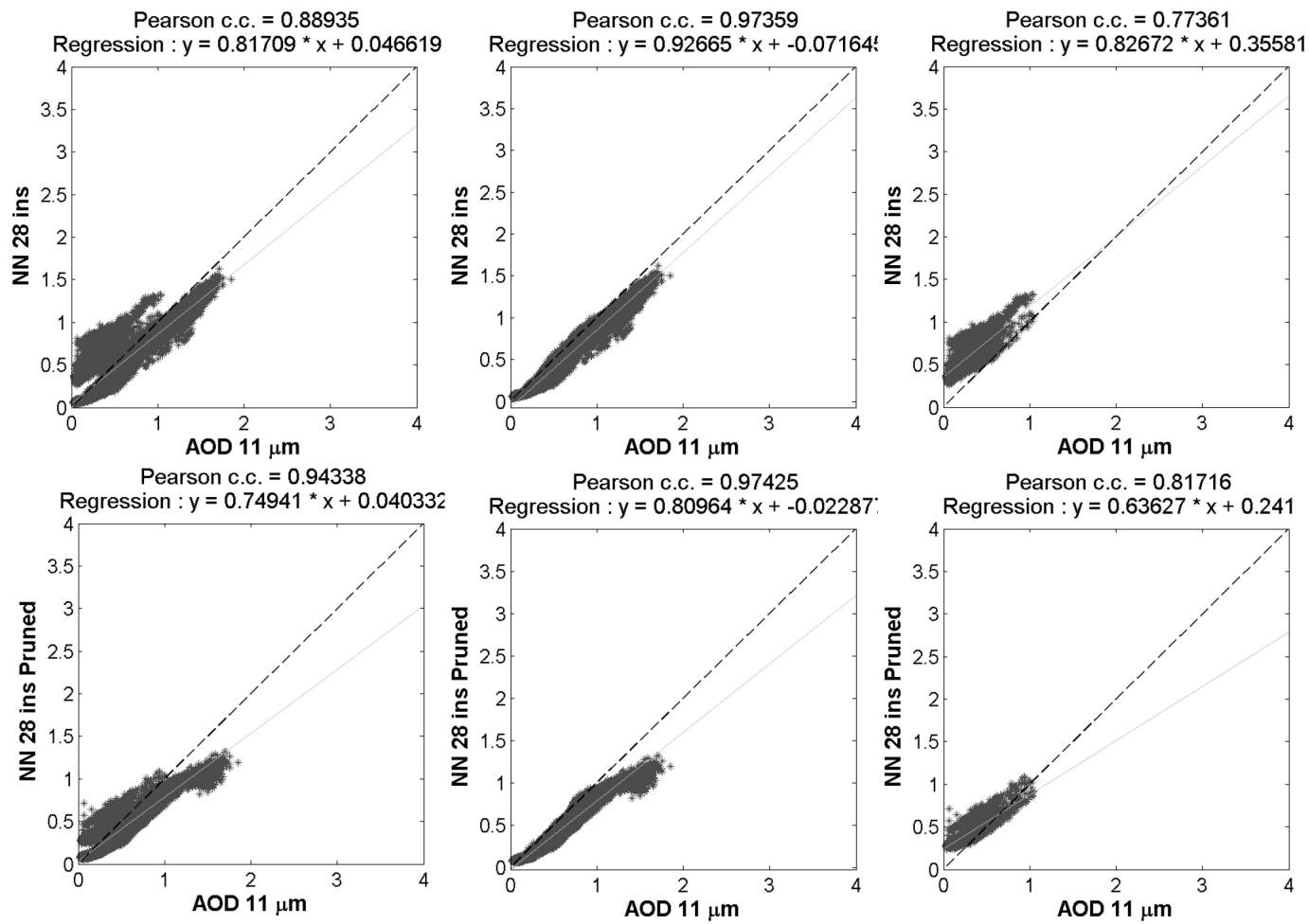

Figure 11. Scatterplots for AOD networks, 3 inputs (top row), 28 inputs (middle row) and 28 inputs pruned (bottom row), applied to the validation set of 11 May 2010, 14:05 UTC, divided into total patterns (left column), patterns over sea (middle column) and patterns over meteorological clouds (right column).

There are not so many formalized studies about pruning techniques comparison; regardless, in the work of Kavzoglu and Mather (1999), it has been shown how magnitude-based (MB) pruning achieves good results compared to other techniques, despite the simplicity of the algorithm. Here, we chose the Optimal Brain Surgeon (OBS) (Stork and Hassibi, 1993), which is an extension of MB that provides improvements in terms of accuracy and stability, despite higher computational effort due to the computation of the inverse of the Hessian matrix to deduce saliency and weight change for every link. There are two criteria for stopping the pruning; the error after each retraining must not exceed the error before the first training more than a certain percentage or the error after each retraining must not exceed a given absolute error value.

The first approach allowed us a more effective selection of the inputs and a reduction of error with respect to the performance of the all-units network initially obtained.

\section{Methodology}

The main objective of the work is to retrieve the three volcanic-ash-related parameters and $\mathrm{SO}_{2}$ total columnar amount by means of NNs, with the MODTRAN-based results as a benchmark, but also to study which are the most effective wavelengths to successfully reach the fixed target. 

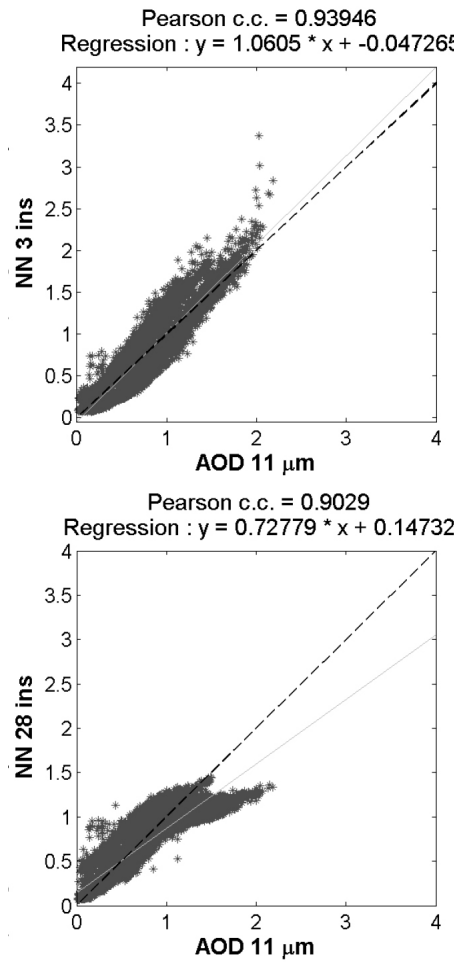

Pearson c.c. $=0.91094$

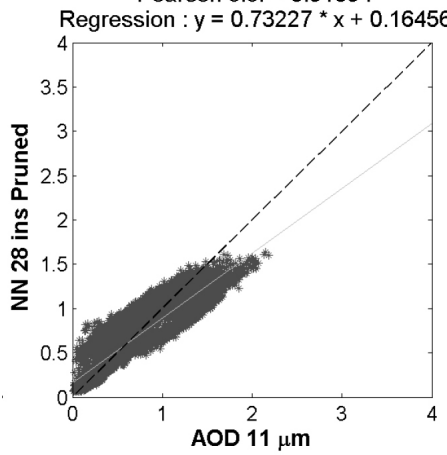

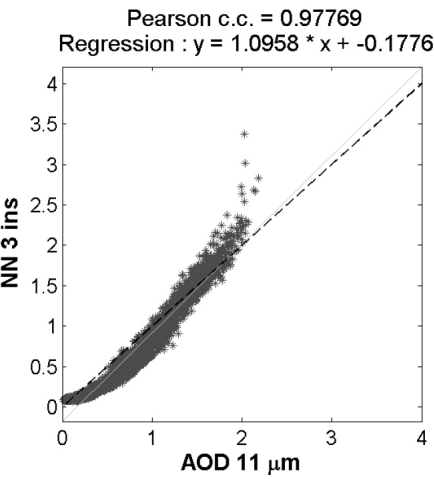

Pearson c.c. $=0.95789$

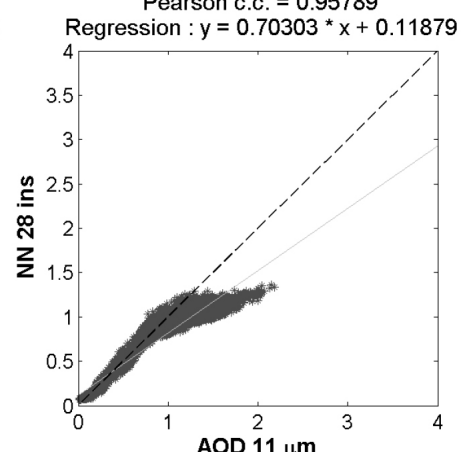

Pearson c.c. $=0.95081$

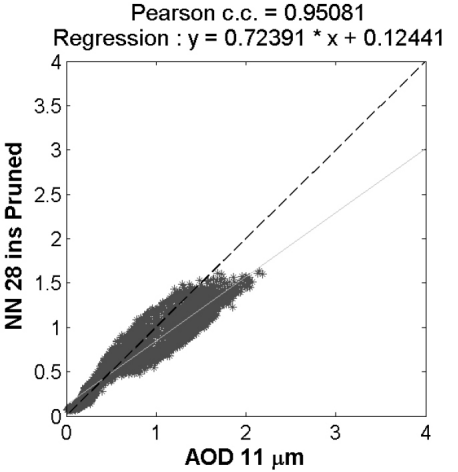

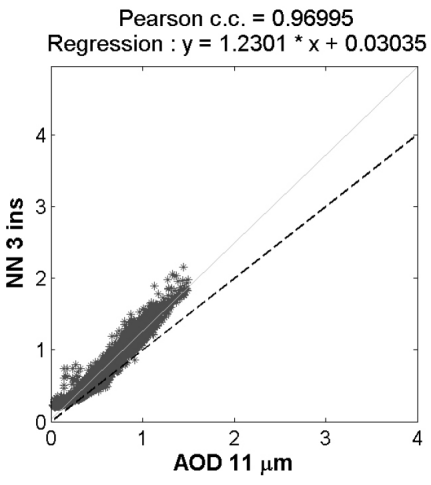
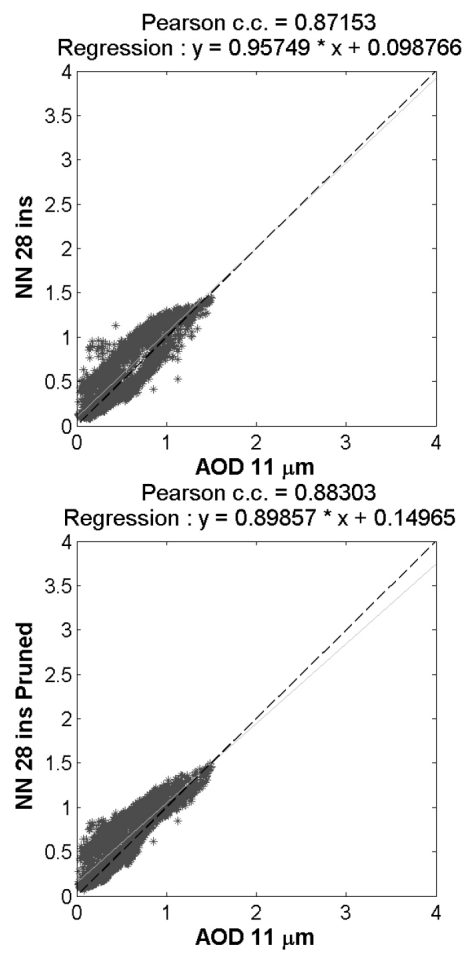

Figure 12. Scatterplots for AOD networks, 3 inputs (top row), 28 inputs (middle row) and 28 inputs pruned (bottom row), applied to the validation set of 12 May 2010, 12:55 UTC, divided into total patterns (left column), patterns over sea (middle column) and patterns over meteorological clouds (right column).

In order to do this, three different NNs have been implemented considering different sets of inputs to exploit both the model approach (i.e., TIR channels) and the full sensor capability. The three NNs are NN-3 which uses the three channels exploited in the physical model; NN-ALL which makes use of all bands provided by MODIS sensors; NN-P which uses the bands selected by the pruning algorithm starting from all available channels. The three MODIS thermal channels for the NN-3 - 31, 32 and 28 - have been suggested by the BTD model, where channel 28 takes into account the water vapor absorption, while for $\mathrm{SO}_{2}$ retrieval, channel 29 centered at $8.7 \mu \mathrm{m}$ has been used instead of 28 .

Even if the systematic identification of the best topology is outside the scope of this study, we have performed a trial and error step to select the best architecture. This optimization step has been done for NN-3 and NN-ALL, and it was mostly focused on finding the best topology for the hidden layers, while the input one is fixed by the number of bands. Both optimization processes have provided the same topology for NN-3 and NN-ALL, one hidden layer of 15 neurons, thus we extended this result to the NN-P, which is completely retrained after the pruning step, only using the selected inputs. In order to focus on the selection of the most significant MODIS channels, the pruning procedure has been applied disabling the possibility to change the $\mathrm{NN}$ hidden layers topology. In this way, the pruning procedure has only been used as a feature selection tool. 

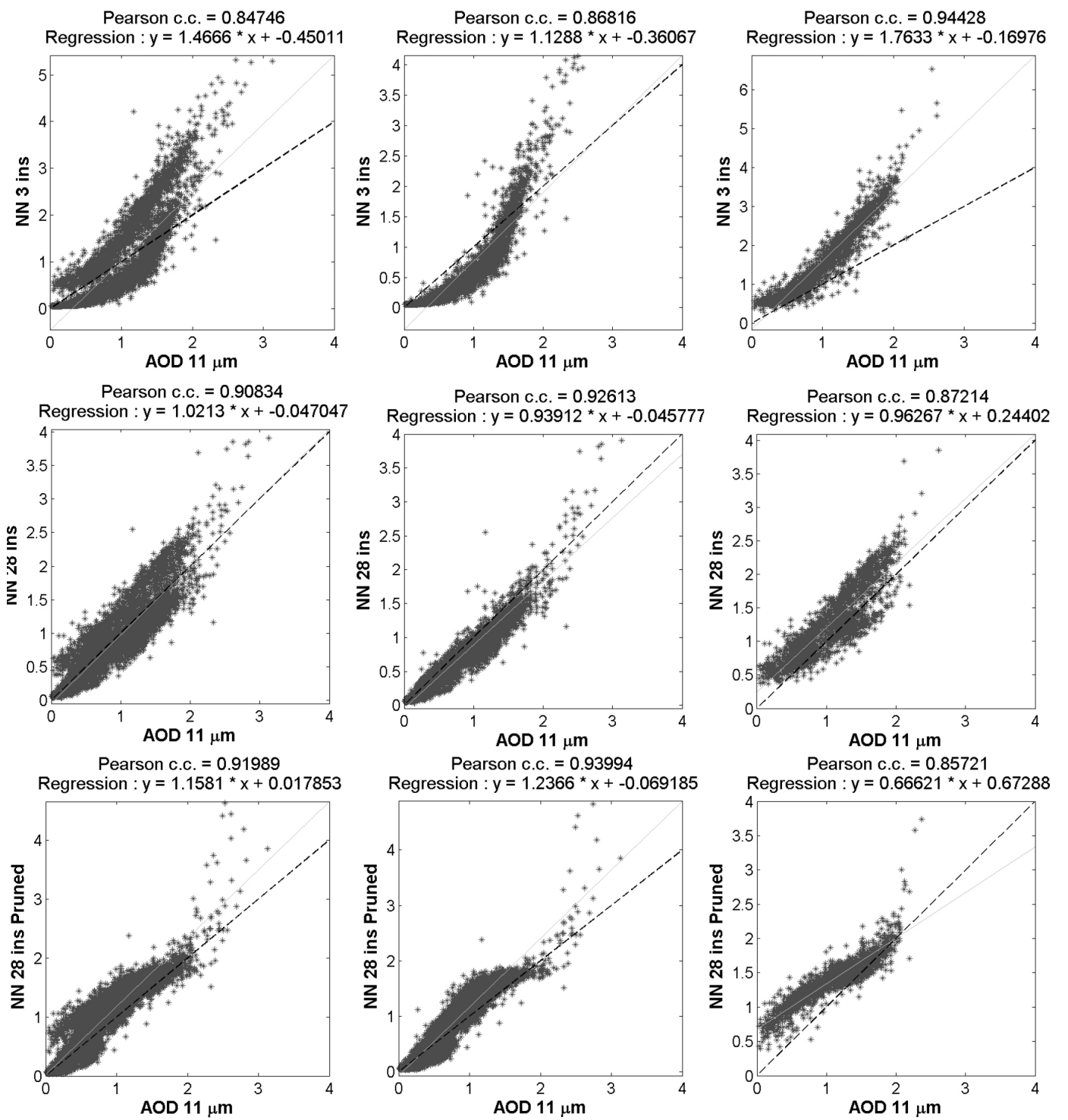

Figure 13. Scatterplots for AOD networks, 3 inputs (top row), 28 inputs (middle row) and 28 inputs pruned (bottom row), applied to the validation set of 16 May 2010, 12:30 UTC, divided into total patterns (left column), patterns over sea (middle column) and patterns over meteorological clouds (right column).

For this study, we collected seven MODIS images related to the third phase of the Eyjafjallajókull eruption, from May 62010 to May 162010 (see Figs. 1 and 2). Therefore, the MODTRAN standard procedures have been used to extract the $\mathrm{SO}_{2}$ and the three ash parameters for all available images.

Since the back-propagation training algorithm is supervised, some examples of the phenomena under investigation are needed. For this purpose, the results of the MODTRANbased inversion have been considered as target output during the training phase. The whole set of MODIS acquisitions has been split into two parts: four dates for the training phase (6, 7, 8 and 13 May, Fig. 3), and the remaining three dates as an independent validation set (11, 12 and 16 May, Fig. 4). This approach has been taken into account for assessing the generalization capabilities of the NNs and the statistical significance of the training and test samples. Indeed, the four training dates have been chosen because of their statistical representativeness of the last eruption phase. The NN retrieval has been focused on the regions in images affected by ash cloud, according to the BTD ash computations, indifferent to the presence of only ash or ash cloud mixed with meteorological clouds. It is worth noticing that the NN retrieval approach has been applied to a real scenario, where meteorological clouds are present as well, introducing additional difficulties in the parameter estimation. Indeed, in the MODTRANbased scheme, the retrieval of all these parameters in such 

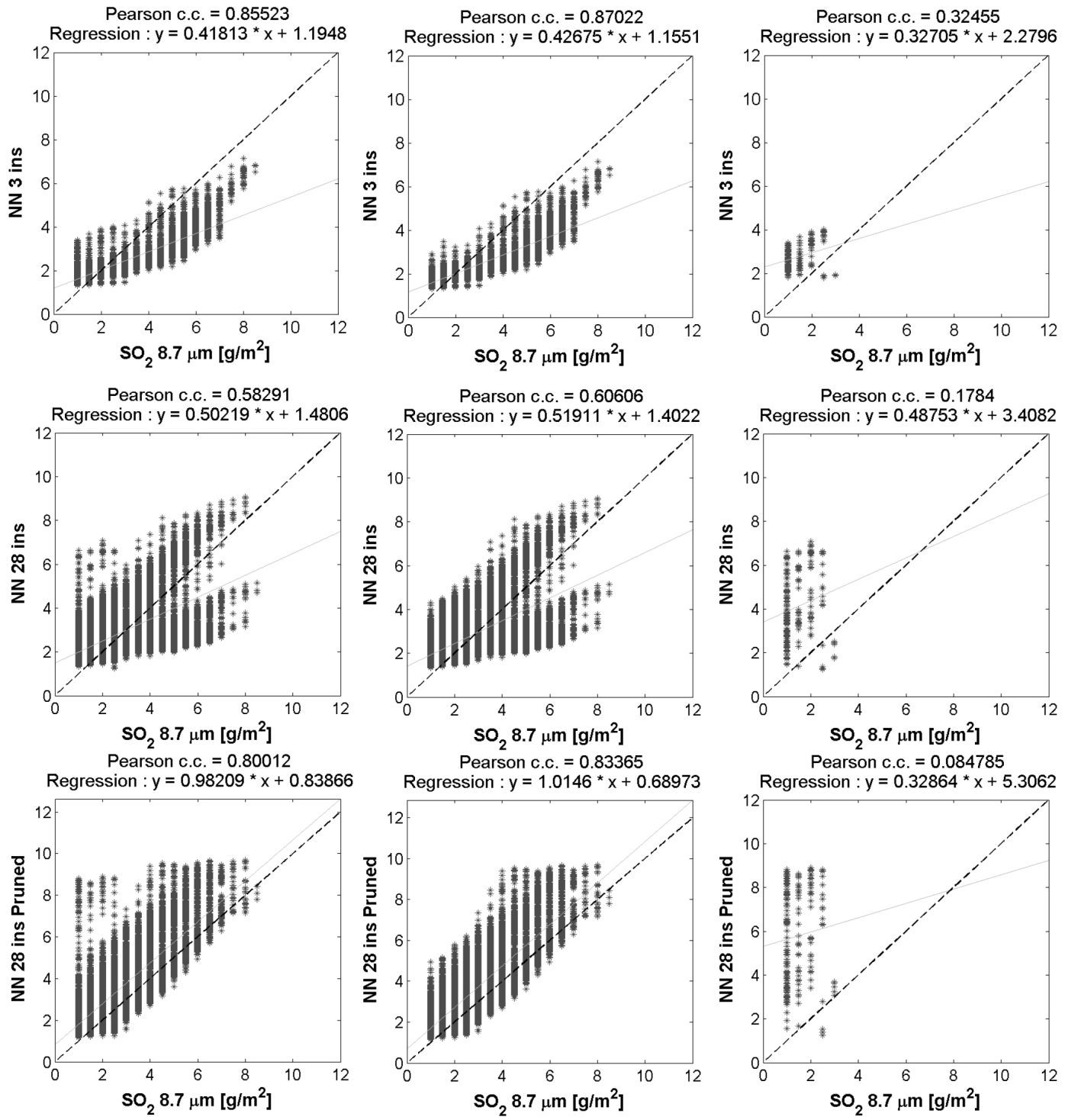

Figure 14. Scatterplots for $\mathrm{SO}_{2}$ networks, 3 inputs (top row), 28 inputs (middle row) and 28 inputs pruned (bottom row), applied to the validation set of 11 May 2010, 14:05 UTC, divided into total patterns (left column), patterns over sea (middle column) and patterns over meteorological clouds (right column).

a condition increases the difficulties of parameterizing the model itself. In particular, the NN training uses pixels from an overlap of meteorological and ash clouds and pixels from volcanic ash above the sea, without disjointing the retrieval problem, while the MODTRAN-based approach has to treat the two cases separately. Validation dates are shown in Tables 4 and 5 . The independent validation pixels have been split further into sea and meteorological clouds, depending on where the ash cloud was located in order to also evaluate the capability of the NNs to deal with these two distinct scenarios. Before this step, the surfaces underlying the ash cloud (sea or meteorological clouds) have been identified by applying a threshold algorithm to the reflectance measured in
MODIS channel 3. This differentiation has not been adopted for the training set since we want to retrieve parameters using a unique neural network.

\section{Results and discussion}

In this section the results obtained by applying the three $\mathrm{NNs}$ (NN-3, NN-ALL and NN-P) for the retrieval of the three ash cloud parameters and $\mathrm{SO}_{2}$ are presented. First, the NN-based retrievals are compared to results obtained by applying the MODTRAN-based approach, and then the performance of the NN retrieval are discussed. 

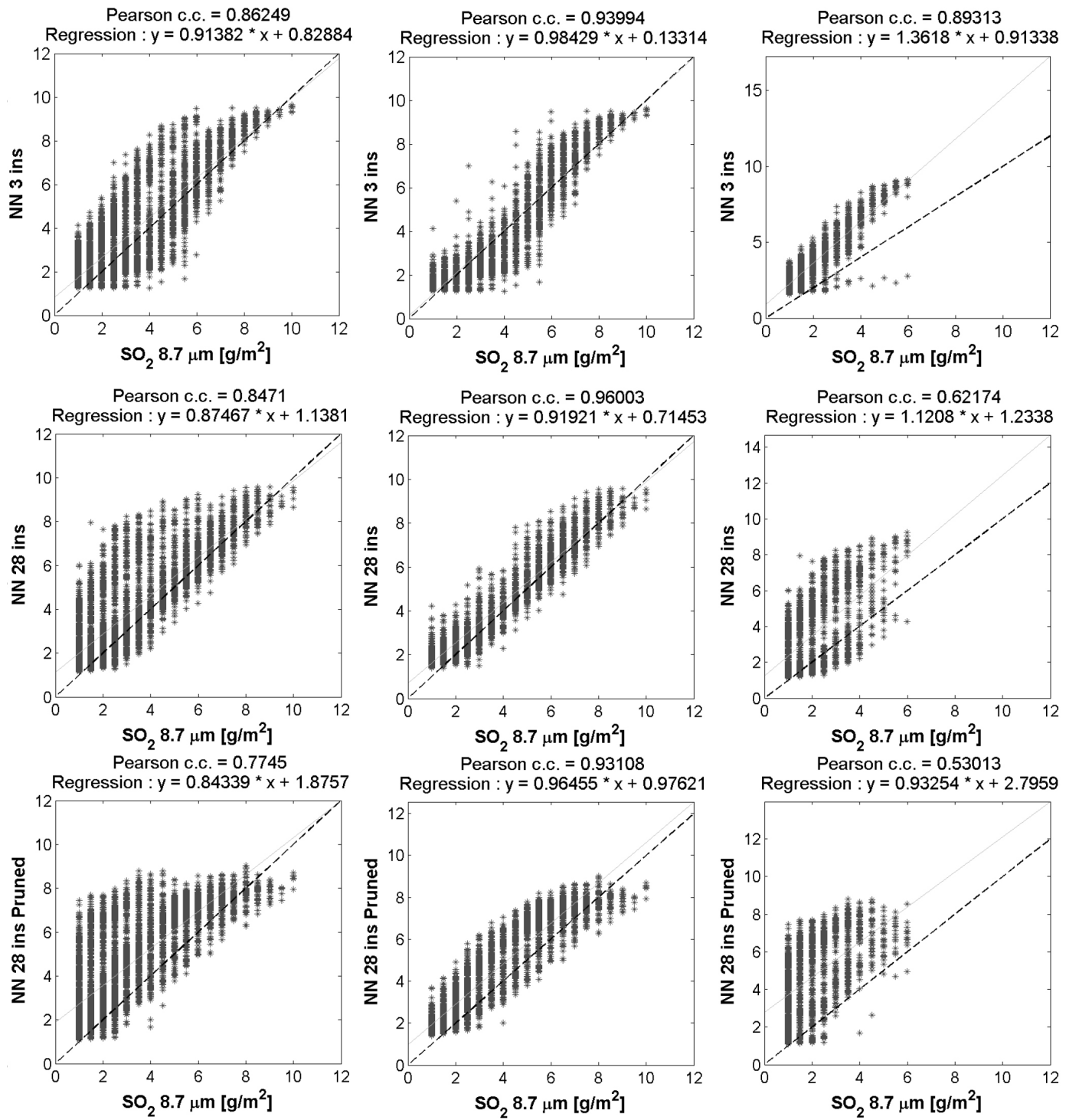

Figure 15. Scatterplots for $\mathrm{SO}_{2}$ networks, 3 inputs (top row), 28 inputs (middle row) and 28 inputs pruned (bottom row), applied to the validation set of 12 May 2010, 12:55 UTC, divided into total patterns (left column), patterns over sea (middle column) and patterns over meteorological clouds (right column).

With regard to the ash parameters, the results are summarized in Tables 6 to 8. As a first general remark, the RMSE of all retrievals is lower than the corresponding SD for all NN configurations (NN-3, NN-ALL and NN-P). This is an indication that the NNs are a valuable approach for this kind of problem. The second remark is that better results are generally obtained with greater-input NNs, namely NN-ALL and NN-P. This second outcome could appear not in agreement with the results obtained by Picchiani et al. (2011) if we compare their results and the present ash mass retrievals. In Picchiani et al. (2011), it seemed that the performance obtained here with NN-ALL and NN-P was already reached with a network based only on the three TIR channels. An explanation can be found considering the lower complexity of the scenario analyzed in the previous work, where the overlapping of volcanic ash and meteorological clouds was not considered.

In Figs. 5 to 16, the scatterplots computed considering the three independent validation sets are shown, and the results of the three NN topologies, i.e., NN-3, NN-ALL and NN-P, are reported for each parameter.

As for the Tables, the scatterplots show the validation set split into two regions, distinguishing the ash plume over sea from that over meteorological clouds, in order to evaluate the performances on the NNs in the two different scenarios. Looking at the scatterplots, the results confirm the findings obtained by Picchiani et al. (2011) for ash mass retrieved above sea, using the three inputs based on physical consider- 

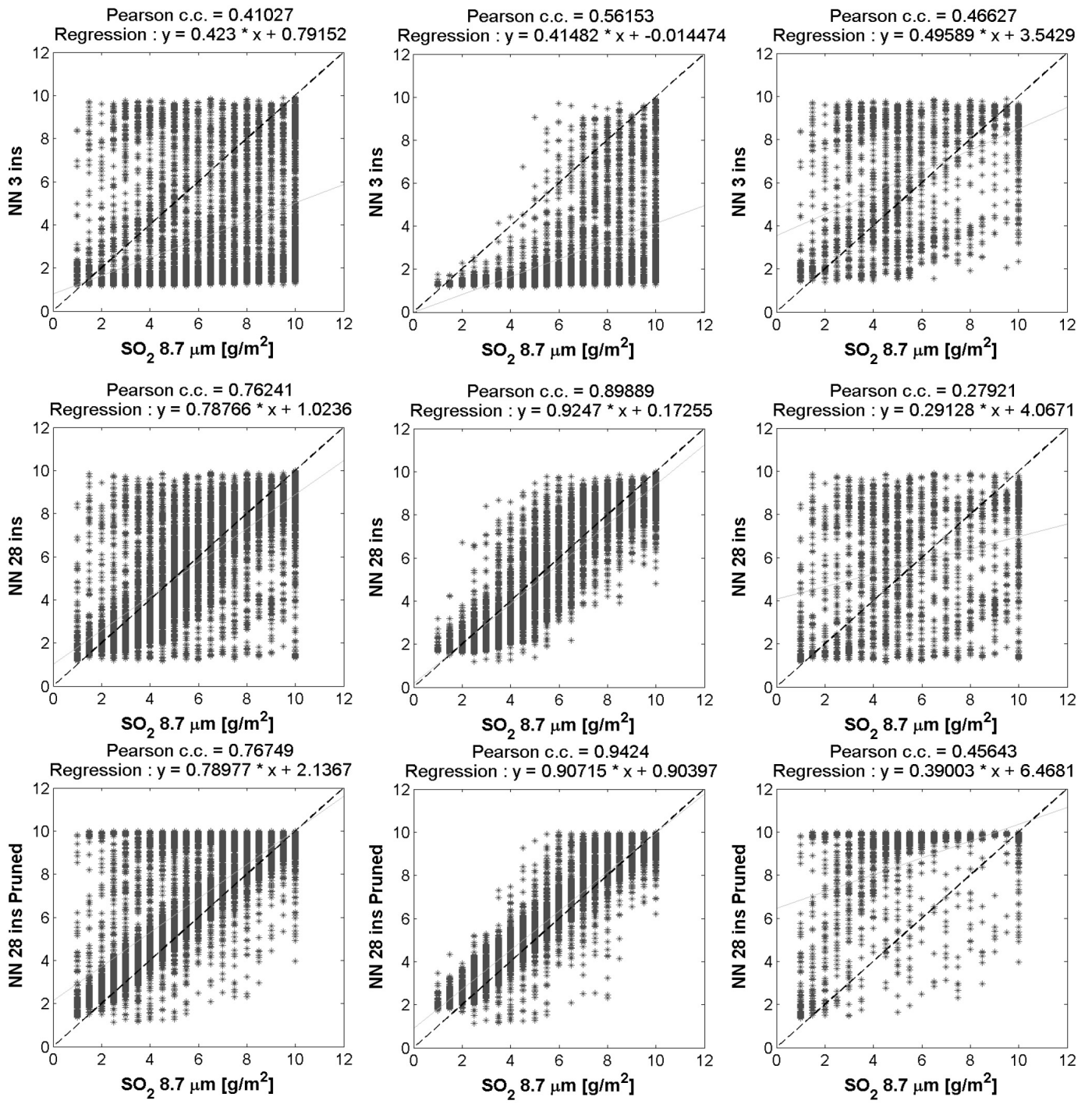

Figure 16. Scatterplots for $\mathrm{SO}_{2}$ networks, 3 inputs (top row), 28 inputs (middle row) and 28 inputs pruned (bottom row), applied to the validation set of 16 May 2010, 12:30 UTC, divided into total patterns (left column), patterns over sea (middle column) and patterns over meteorological clouds (right column).

ations. Moreover, they prove the effectiveness of the methodology for the other parameters and in a more complex physical scenario. The scatterplots also show a general capability of the $\mathrm{NN}$ approach for reproducing the retrieval obtained by the radiative transfer model inversion. There is a certain degree of underestimation characterizing all parameters for all test dates. The patterns above meteorological clouds show a lower accuracy than the patterns above sea. The high error of NN inversions depends on the higher uncertainty of the BTD retrieval procedure in the presence of a meteorological cloud due to the non-homogeneity of the meteorological cloud itself. Moreover, for the temperature at the cloud top, the brightness temperature has been considered instead of the physical temperature. This approximation is more reasonable for higher clouds.
A deeper comparison of all three $\mathrm{NN}$ topologies shows that better performances above sea are obtained when the spectral information increases (NN-ALL and NN-P).

As expected and confirmed by experimental results, the NN-ALL and NN-P provided almost the same results, since in the procedure, to obtain the NN-P from the NN-ALL, we tried to decrease the number of inputs without affecting the retrieval capabilities. In this way, redundant information is neglected, allowing the network to be trained faster and to obtain a better generalization of independent test cases. This conclusion is confirmed by the results obtained applying NNs to the validation date of 16 May 2010. Indeed, the inputs selected by the pruning allow one to achieve better accuracies for ash parameters and $\mathrm{SO}_{2}$ retrieval when data outside the time frame used to train the model are considered. This re- 

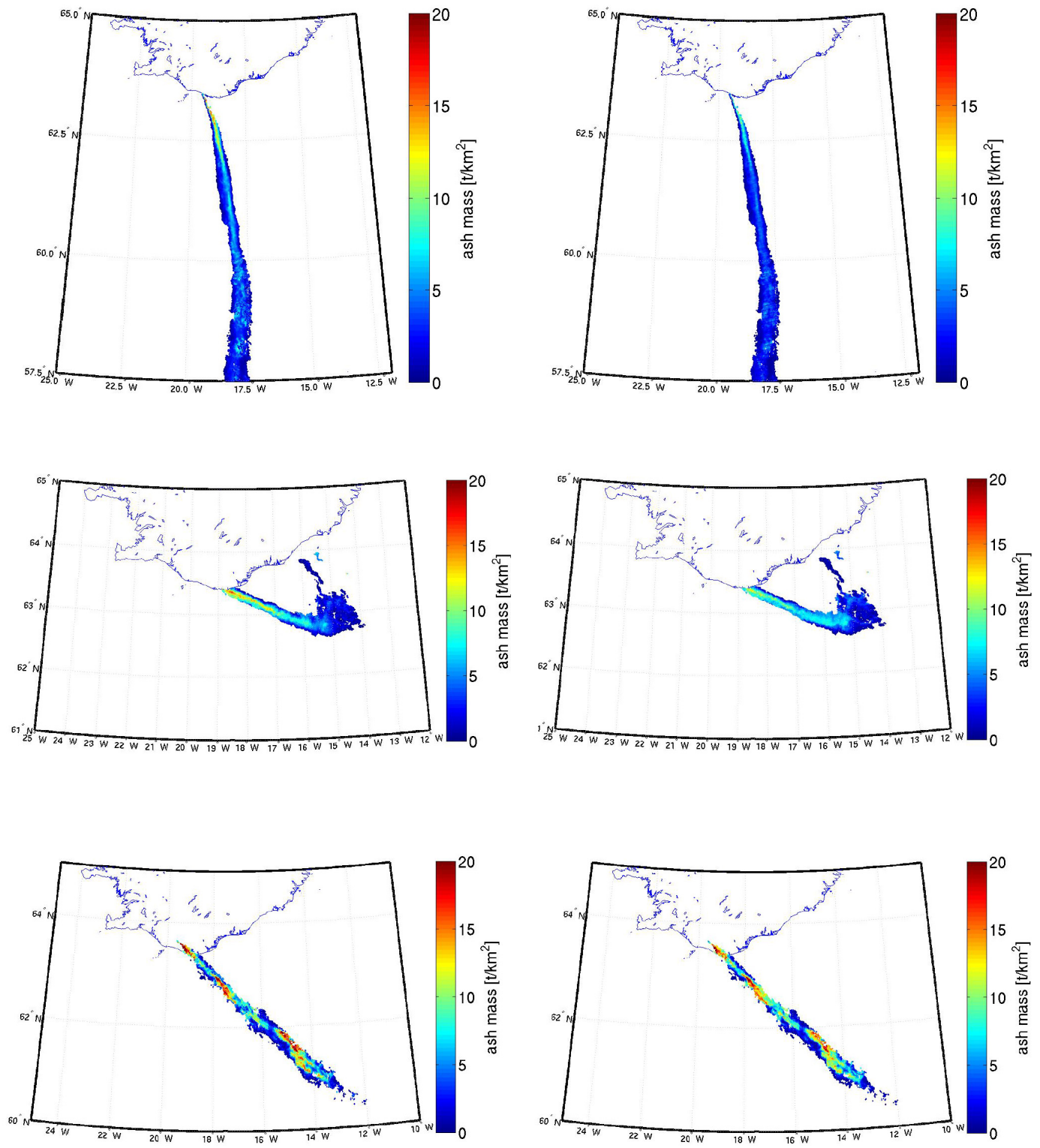

Figure 17. Ash mass maps: top, 11 May 2010; middle, 12 May 2010; bottom, 16 May 2010. Left: target retrieval; right: retrieval from pruned neural network.

sult is particularly evident for the $\mathrm{SO}_{2}$ case in which the NN3 performance is worse for both ash over sea and ash over meteorological clouds (see Fig. 16). In Table 9, all bands selected by the procedure are summarized, and it is possible to see that the pruning selection has always included the MODIS channels with the highest physical information, i.e., channels 31 and 32. For all three parameters, the pruning step selects around $50 \%$ of the input space. In particular, the most common MODIS channels selected by the pruning procedure applied to the different ash parameters are as follows: channels 1, 3 and 4 are sensitive to the very fine ash; channels 23 and 25 are sensitive to cloud surface and atmospheric temper- ature, respectively; channel 36 is sensitive to the cloud-top altitude.

The NN-P maps (Figs. 17, 18 and 19), representing the best results obtained for all three parameters, have been compared to the model-based results for the two validation dates. Looking at the figures, the good performance of the NN approach is confirmed for the three ash parameters; in fact, the MODTRAN-based results were the same as those produced by the NN-P. With regard to $\mathrm{SO}_{2}$, RMSE is still lower than $\mathrm{SD}$ of parameter distribution, even if it is higher with respect to the ash parameters, especially in the meteorological clouds' case (see Tables 6, 7 and 8). Looking at the scatterplots (Figs. 14, 15 and 16), if we focus our attention only on 

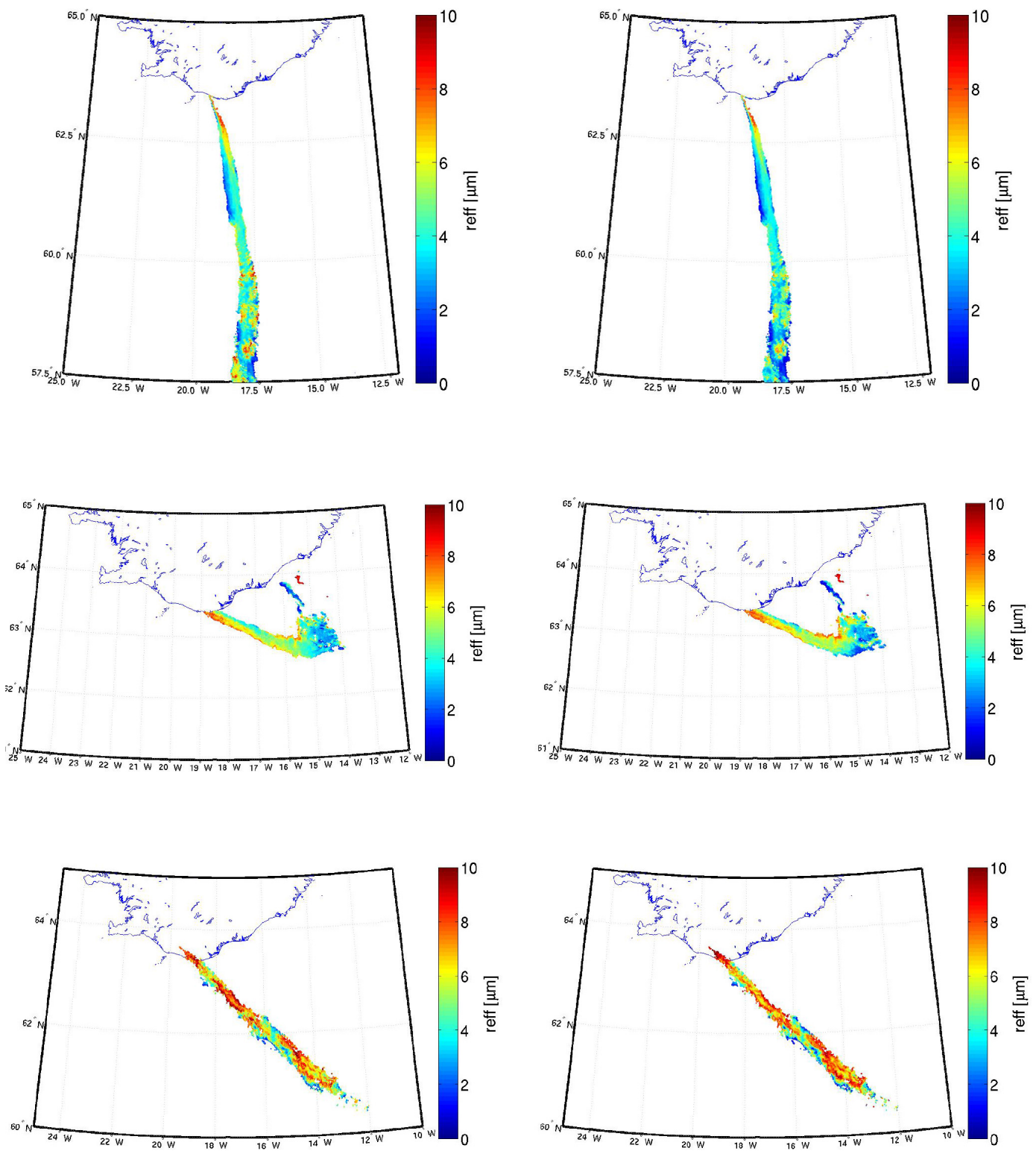

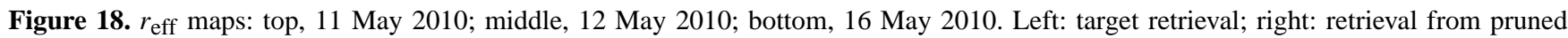
neural network.

the $\mathrm{SO}_{2}$ above the sea, results are better if we increase the number of inputs, while with the meteorological cloud some problems are still present. Indeed, the retrieval above meteorological clouds is not satisfactory with $\mathrm{NN}-3$, and it does not improve if we increase the number of inputs (Figs. 14, 15 and 16 , right column).

In Figs. 20, 21 and 22, the comparison between the modelbased and the NN results maps is reported. In these cases, both NN-3 and NN-P results highlight that the pruning analysis in general does not improve the results obtained considering only three channels, or it improves them slightly, in particular when the volcanic cloud lies above the meteorological clouds (see Fig. 21). Nevertheless, looking at Fig. 20, where
NN has been applied to validation date of 11 May 2010, the retrieval obtained by NN-P shows higher accuracy than that obtained by NN-3, while for the date of 16 May 2010, the information added by the other channels seems to achieve a better generalization of the $\mathrm{NN}$.

The reason for the better NN ash retrieval performance and for the worse one in case of $\mathrm{SO}_{2}$ retrieval, when the addition of different MODIS channels is considered, might be explained by the different selective interactions between the two species in the wavelengths from VIS to TIR. The aerosol particles, such as volcanic ash, do not present a defined spectral signature at specific wavelengths, but they interact (with absorption and scattering) continuously over the 

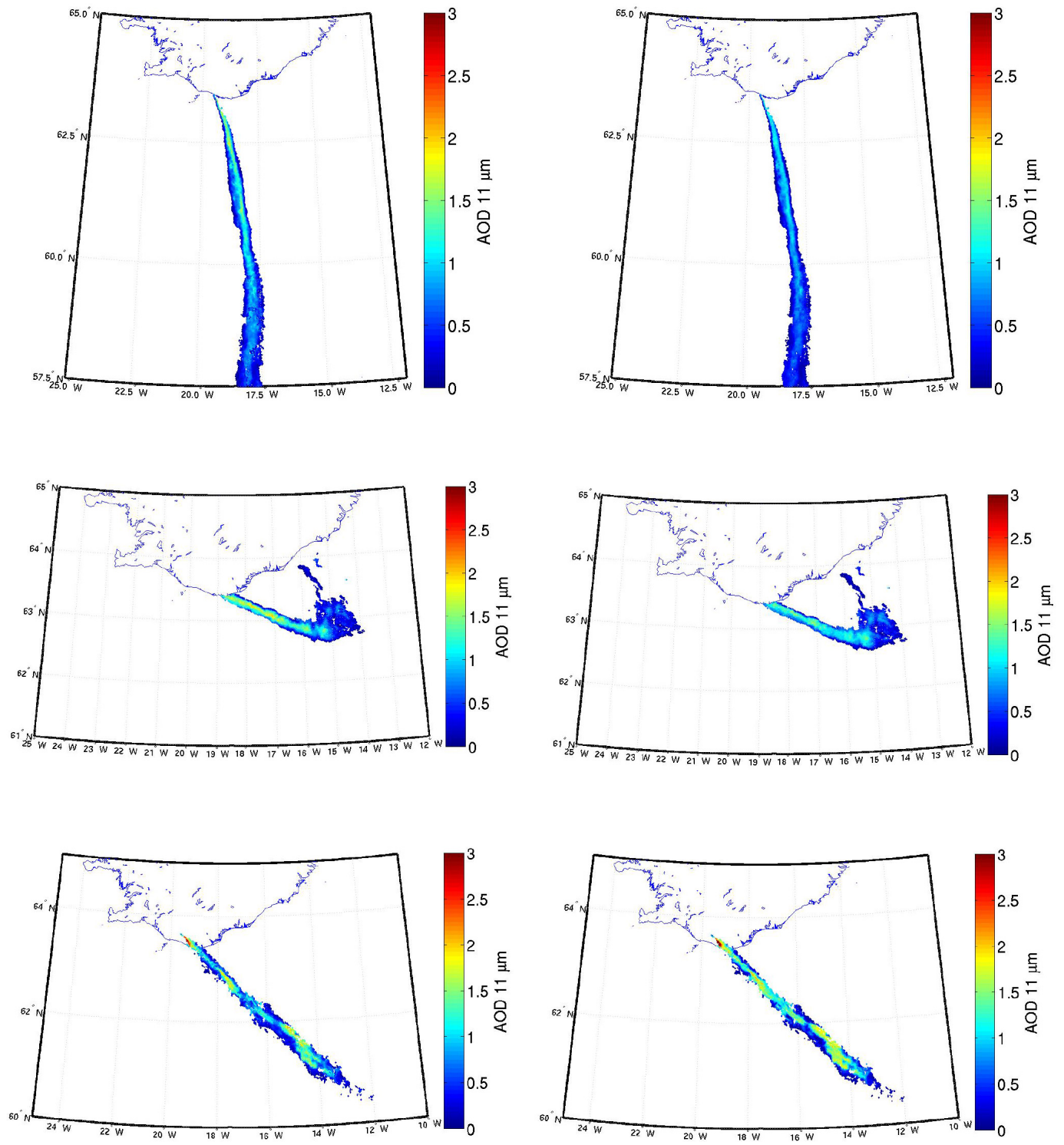

Figure 19. AOD maps: top, 11 May 2010; middle, 12 May 2010; bottom, 16 May 2010. Left: target retrieval; right: retrieval from pruned neural network.

whole VIS-TIR spectral range. In this case, the addition of channels will increase, even if only slightly, the information content of the ash presence in the atmosphere. Conversely, $\mathrm{SO}_{2}$ presents spectral signatures more sensitive to specific wavelengths, thus increasing the number of input channels outside the absorption signature the noise will increase without improving the information content.

\section{Conclusions}

The NNs have been effective in solving the inversion problem related to the estimation of the volcanic cloud parameters, addressing the issue related to presence of false alarms in the detection of volcanic ash. Moreover, once the train- ing phase is completed, NNs have been proven to be a fast retrieval technique, which is very useful at the application stage. From this point of view, the technique satisfies the need to provide results quickly in case of disastrous natural events, such as volcanic eruptions.

Volcanic ash and $\mathrm{SO}_{2}$ clouds were detected and characterized over sea and over meteorological clouds simultaneously, where the latter represents a very essential condition for running the RTM-based approach. The results confirm the effectiveness of the approach especially considering the main goal of obtaining an accurate retrieval for the plume above the sea. We have proven that the simplified topology obtained by considering only three input channels is almost unable to describe the complexity of the considered scenario and that 

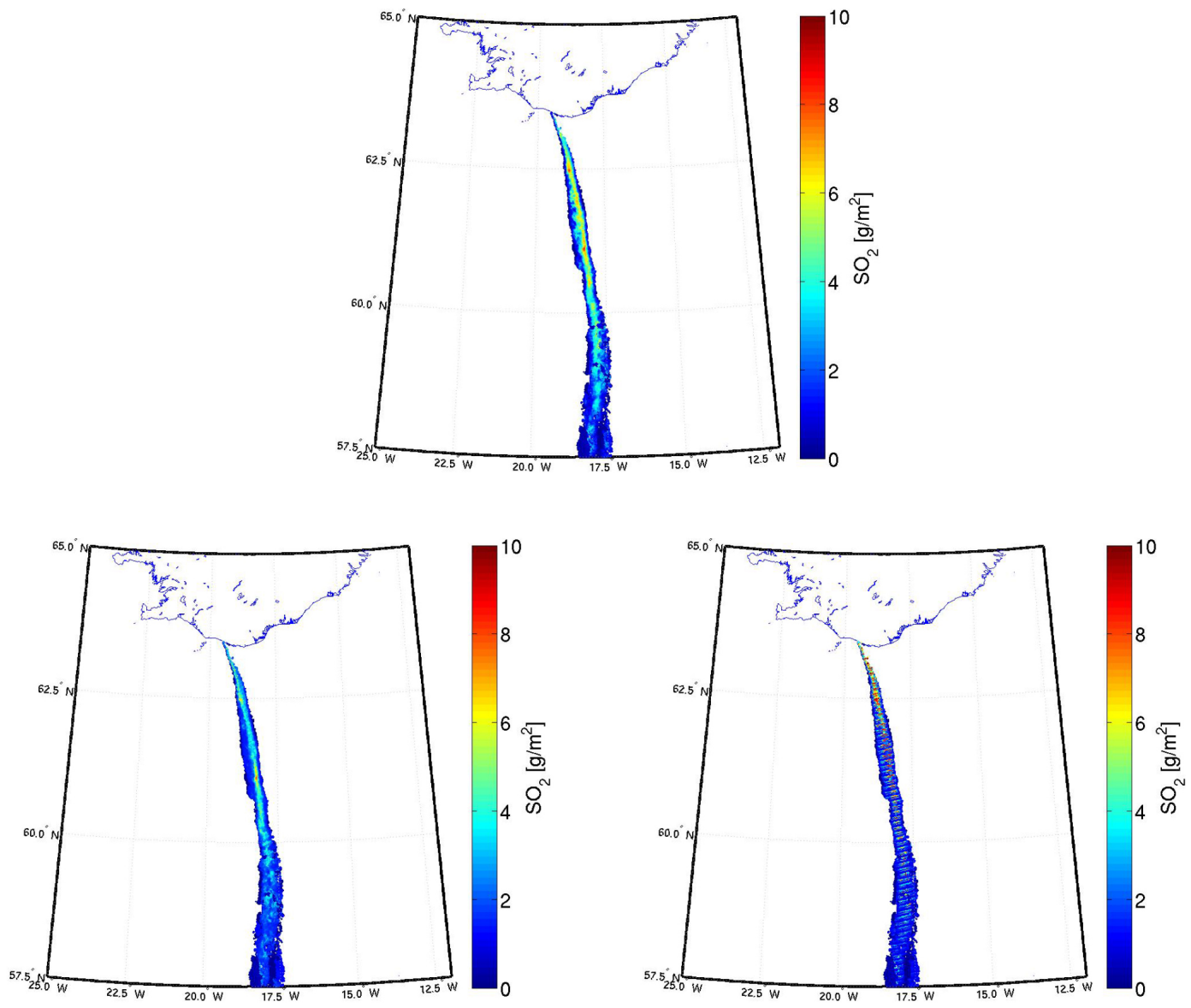

Figure 20. $\mathrm{SO}_{2}$ columnar abundance maps for 11 May 2010: top, target retrieval; bottom left, retrieval from 3 inputs neural network; bottom right, retrieval from pruned neural network.

pruning analysis can be conveniently applied to find other significant input channels and improve NN performance accuracy.

Moreover, the increase in the number of inputs with other MODIS channels improves the ash retrieval over the sea and provides appreciable results on patterns characterized by meteorological clouds. Another remarkable outcome is that the retrieval accuracy over the sea is not compromised by the presence of meteorological clouds underlying the ash cloud in the training set, allowing one to apply a unique NN without splitting the problem as required by the MODTRANbased algorithm. Indeed, it seems that the NNs estimate the main relationship between ash characteristics and radiometric measurement, despite the presence of effects due to meteorological clouds. Especially for the ash parameters, the majority of the validation pixels were properly retrieved in both the scenarios. The spread shown in the scatterplots, describing pixels above meteorological clouds, is due to some boundary effects on the region between the ash cloud and meteorological clouds. This behavior can be interpreted as a posteriori validation of the forward model accuracy over me- teorological clouds, indeed it seems that the NNs address the core of the plume on the clouds quite well, where the forward model gives good results, and fails to retrieve ash boundary pixels, characterized by mixed effects of ash and clouds, confirming high uncertainty of the forward model in describing such a complex scenario.

On the other hand, the pruning analysis was able to apply a feature selection of input data set maintaining the significant inputs and improving the accuracy of the $\mathrm{NN}$ or by leaving it unaltered.

Results obtained for $\mathrm{SO}_{2}$ with the same approach are generally in agreement with those obtained for the three ash parameters, even if some problems still remain above the meteorological clouds. Nevertheless, for the validation date on 16 May 2010, the pruning technique succeeds in finding the significant inputs improving the NN results that are completely unsatisfactory for the three channels approach.

Future studies will include testing the usefulness of the technique under different light conditions (nighttime) and on different multispectral remote sensed data, such as those provided by high-revisit time sensors like MSG-SEVIRI, on 

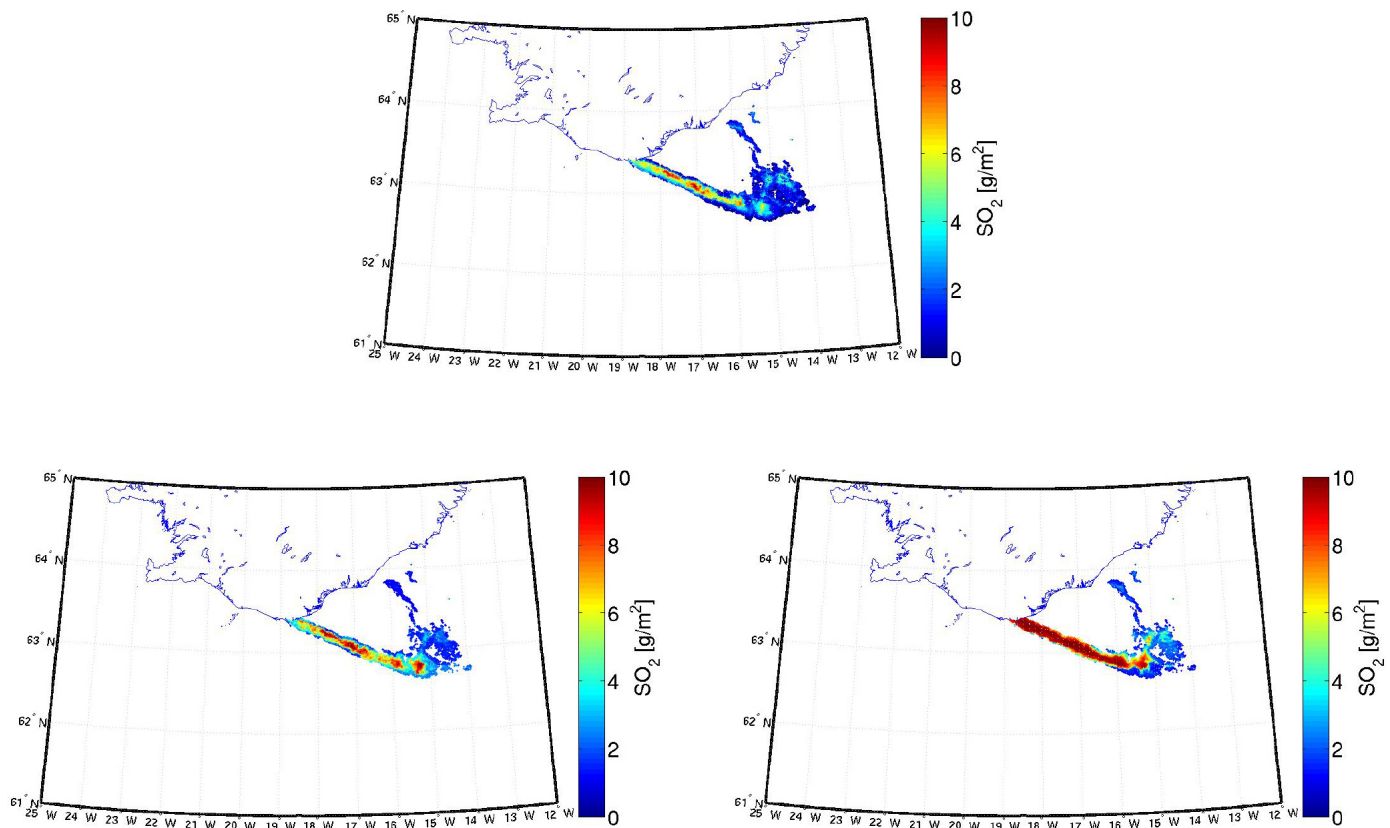

Figure 21. $\mathrm{SO}_{2}$ columnar abundance maps for 12 May 2010: top, target retrieval; bottom left, retrieval from 3 inputs neural network; bottom right, retrieval from pruned neural network.
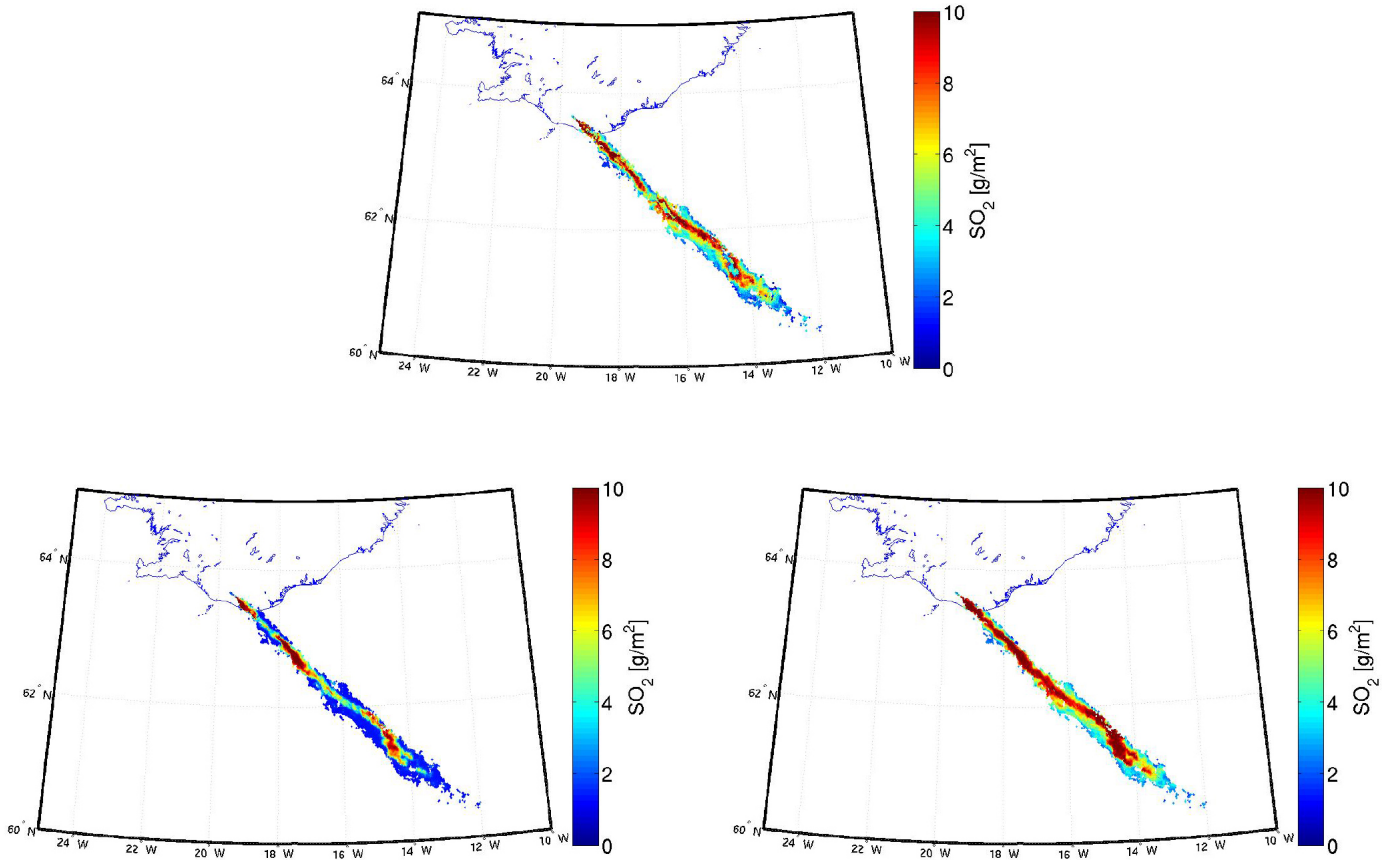

Figure 22. $\mathrm{SO}_{2}$ columnar abundance maps for 16 May 2010: top, target retrieval; bottom left, retrieval from 3 inputs neural network; bottom right, retrieval from pruned neural network. 
board the METEOSAT Second Generation satellites. The latter would be particularly suitable for its extremely quick response which is a key property for realtime monitoring the atmosphere.

Acknowledgements. M. Chini's contribution was supported by the National Research Fund of Luxembourg through the PAPARAZZI project (CORE C11/SR/1277979).

The authors would like to thank the reviewers for their helpful comments and Sally Louise Baldwin for partially revising the English text.

Edited by: F. S. Marzano

\section{References}

Allard, P., Carbonnelle, J., Metrich, N., Loyer, H., and Zettwoog, P.: Sulphur output and magma degassing budget of Stromboli volcano, Nature, 368, 326-330, 1994.

Anderson, G. P., Wang, J., and Chrtwynd, J. H.: MODTRAN3: An update and recent validation against airborne high resolution inferometer measurements, In Summaries of the Fifth Annual Jet Propulsion Laboratory Airborne Earth Science Workshop, 95-1(1), 5-8, 1995.

Atkinson, P. M. and Tatnall, A. R. L.: Neural networks in remote sensing, Int. J. Remote Sens., 18, 699-709, 1997.

Bankert, R. L.: Cloud classification of AVHRR imagery in maritime regions using a probabilistic neural network, J. Appl. Meteorol., 33, 909-918, 1994.

Barnes, W. L., Pagano, T. S., and Salomonson, V. V.: Prelaunch characteristics of the ModerateResolution Imaging Spectroradiometer (MODIS) on EOS-AMI, IEEE T. Geosci. Remote Sens., 36, 1088-1100, 1998.

Berk, A., Bernstein, L. S., and Robertson, D. C.: MODTRAN: A Moderate Resolution Model for LOWTRAN 7, 1989.

Bishop, C. M.: Neural Networks for Pattern Recognition, Oxford University Press, 1995.

Blackwell, W. J.: A neural-network technique for the retrieval of atmospheric temperature and moisture profiles from high spectral resolution sounding data, IEEE T. Geosci. Remote Sens., 43, 2535-2546, 2005.

Butler, C. T., Meredith, R. V. Z., and Stogryn, A. P.: Retrieving atmospheric temperature parameters from DMSP SSM/T-1 data with a neural network, J. Geophys. Res., 101, 7075-7083, 1996.

Cabrera-Mercader, C. R. and Staelin, D. H.: Passive microwave relative humidity retrievals using feed forward neural networks, IEEE T. Geosci. Remote Sens., 33, 1324-1328, 1995.

Churnside, J. H., Stermitz, T. A., and Schroeder, J. A.: Temperature profiling with neural network inversion of microwave radiometer data, J. Atmos. Oceanic Technol., 11, 105-109, 1994.

Corradini, S., Pugnaghi, S., Teggi, S., Buongiorno, M. F., and Bogliolo, M. P.: Will ASTER see Etna $\mathrm{SO}_{2}$ plume?, Int. J. Remote Sens., 24, 1207-1218, 2003.

Corradini, S., Spinetti, C., Carboni, E., Tirelli, C., Buongiorno, M. F., Pugnaghi, S., and Gangale, G.: Mt. Etna tropospheric ash retrieval and sensitivity analysis using Moderate Resolution Imag- ing Spectroradiometer measurements, J. Appl. Remote Sens., 2, 023550, doi:10.1117/1.3046674, 2008.

Corradini, S., Merucci, L., and Prata, A. J.: Retrieval of $\mathrm{SO}_{2}$ from thermal infrared satellite measurements: correction procedures for the effects of volcanic ash, Atmos. Meas. Tech., 2, 177-191, doi:10.5194/amt-2-177-2009, 2009.

Corradini, S., Merucci, L., Prata, A. J., and Piscini, A.: Volcanic ash and $\mathrm{SO}_{2}$ in the 2008 Kasatochi eruption: Retrievals comparison from different IR satellite sensors, J. Geophys. Res., 115, D00L21, doi:10.1029/2009JD013634, 2010.

Corradini, S., Merucci, L., and Arnau, F.: Volcanic ash cloud properties: comparison between MODIS satellite retrievals and FALL3D transport model, IEEE Geosci. Remote Sens., 8, 248-252, 2011.

Cybenko, G.: Approximation by superpositions of a sigmoidal function, Math. Control, Signals, Syst., 2, 303-314, 1989.

Del Frate, F. and Schiavon, G.: Nonlinear principal component analysis for the radiometric inversion of atmospheric profiles by using neural networks, IEEE T. Geosci. Remote Sens., 37, 2335-2342, 1999.

Del Frate, F., Ortenzi, A., Casadio, S., and Zehner, C.: Application of neural algorithms for a real-time estimation of ozone profiles from GOME measurements, IEEE T. Geosci. Remote Sens., 40, 2263-2270, 2002.

Del Frate, F., Iapaolo, M., Casadio, S., Godin-Beekmann, S., and Petitdidier, M.: Neural networks for the dimensionality reduction of GOME measurement vector in the estimation of ozone profiles, J. Quant. Spectrosc. Ra., 92, 275-291, 2005.

Edmonds, M., Aiuppa, A., Humphreys, M., Moretti, R., Giudice, G., Martin, R. S., Herd, R. A., and Christopher, T.: Excess volatiles supplied by mingling of mafic magma at an andesite arc volcano, Geochem. Geophys. Geosyst., 11, Q04005, doi:10.1029/2009GC002781, 2010.

Foody, G. M.: Using prior knowledge in artificial neural network classification with a minimal training set, Int. J. Remote Sens, 16, 301-312, 1995.

Gardner, M. W. and Dorling, S. R.: Artificial neural networks (the multilayer perceptron) - A review of applications in the atmospheric sciences, Atmos. Environ., 32, 2627-2636, 1998.

Gudmundsson, M. T., Pedersen, R., Vogfjörd, K., Thorbjarnardóttir, B., Jakobsdóttir, S. S., and Roberts, M. J.: Eruptions in Eyjafjallajökull Volcano, Iceland: EOS (Transaction American Geophysical Union), 91, 190-191, doi:10.1029/2010EO210002, 2010.

Haykin, S.: Neural Networks: A Comprehensive Foundation, Macmillan, New York, 1994.

Hillger, D. W. and Clark, J. D.: Principal component image analysis of MODIS for volcanic ash. Part I: Most important bands and implications for future GOES imagers, J. Appl. Meteorol., 41, 985-1001, 2002.

Horwell, C. J. and Baxter, P. J.: The respiratory health hazards of volcanic ash: A review for volcanic risk mitigation, Bull. Volcanol., 69, 1-24, doi:10.1007/s00445-006-0052-y, 2006.

Hsieh, W. W. and Tang, B.: Applying neural network models to prediction and data analysis in meteorology and oceanography, B. Am. Meteorol. Soc., 79, 1855-1870, 1998.

Kavzoglu, T. and Mather, P. M.: Pruning artificial neural networks: An example using land cover classification of multi-sensor images, Int. J. Remote Sens., 20, 2787-2803, 1999. 
Krasnopolsky, V. M., Breaker, L. C., and Gemmill, W. H.: A neural network as a nonlinear transfer function model for retrieving surface wind speeds from the special sensor microwave imager, J. Geophys. Res., 100, 11033-11045, 1995.

Lee, J., Weger, R. C., Sengupta, S. K., and Welch, R. M.: A neural network approach to cloud classification, IEEE T. Geosci. Remote Sens., 28, 846-855, 1990.

Mas, J. F. and Flores, J. J.: The application of artificial neural networks to the analysis of remotely sensed data, Int. J. Remote Sens, 29, 617-663, 2008.

Merucci, L., Burton, M., Corradini, S., and Salerno, G. G.: Reconstruction of $\mathrm{SO}_{2}$ flux emission chronology from space-based measurements, J. Volcanol. Geotherm. Res., 206, 80-87, 2011.

Miller, T. P. and Casadevall, T. J.: Volcanic ash hazards to aviation, in: Encyclopedia of Volcanoes, edited by: Sigurdsson, H., San Diego, Academic Press, 915-930, 2000.

Müller, M. D., Kaifel, A. K., Weber, M., Tellmann, S., Burrows, J. P., and Loyola, D.: Ozone profile retrieval from Global Ozone Monitoring Experiment (GOME) data using a neural network approach (Neural Network Ozone Retrieval System (NNORSY)), J. Geophys. Res., 108, 4497, doi:10.1029/2002JD002784, 2003.

Pacifici, F., Chini, M., and Emery, W. J.: A neural network approach using multi-scale textural metrics from very high resolution panchromatic imagery for urban land-use classification, Remote Sens. Environ., 113, 1276-1292, 2009.

Picchiani, M., Chini, M., Corradini, S., Merucci, L., Sellitto, P., Del Frate, F., and Stramondo, S.: Volcanic ash detection and retrievals using MODIS data by means of neural networks, Atmos. Meas. Tech., 4, 2619-2631, doi:10.5194/amt-4-2619-2011, 2011.

Picchiani, M., Del Frate, F., Schiavon, G., and Stramondo, S.: Features extraction from SAR interferograms for tectonic applications, EURASIP Journal on Advances in Signal Processing, 2012, 1-13, 2012.

Pollack, J. B., Toon, O. B., and Khare, B. N.: Optical properties of some terrestrial rocks and glasses, Icarus, 19, 372-389 doi:10.1016/0019-1035(73)90115-2, 1973.

Prata, A. J.: Observations of volcanic ash clouds in the 10-12 mm window using AVHRR/2 data, Int. J. Remote Sens., 10, 751-761, 1989a.

Prata, A. J.: Infrared radiative transfer calculations for volcanic ash clouds, Geophys. Res. Lett., 16, 1293-1296, 1989b.

Prata, A. J. and Kerkmann, J.: Simultaneous retrieval of volcanic ash and $\mathrm{SO}_{2}$ using MSG-SEVIRI measurements, Geophys. Res. Lett., 34, L05813, doi:10.1029/2006GL028691, 2007.

Pugnaghi, S., Gangale, G., Corradini, S., and Buongiorno, M. F.: Mt. Etna sulfur dioxide flux monitoring using ASTER-TIR data and atmospheric observations. J. Volcanol. Geotherm. Res., 152, 74-90, 2006,

Realmuto, V. J., Abrams, M. J., Buongiorno, M. F., and Pieri, D. C.: The use of multispectral thermal infrared image data to estimate the sulfur dioxide flux from volcanoes: A case study from Mount Etna, Sicily, July 29, 1986, J. Geophys. Res., 99, 481-488, 1994.
Realmuto, V. J., Sutton, A. J., and Elias, T.: Multispectral thermal infrared mapping of sulfur dioxide plumes: A case study from the East Rift Zone of Kilauea Volcano, Hawaii, J. Geophys. Res., 102, 15057-15072, 1997.

Robock, A.: Volcanic eruptions and climate, Rev. Geophys., 38, 191-219, 2000.

Salerno, G. G., Burton, M. R., Oppenheimer, C., Caltabiano, T., Randazzo, D., Bruno, N., and Longo, V.: Threeyears of $\mathrm{SO}_{2}$ flux measurements of Mt. Etna using an automated UV scanner, J. Volcanol. Geotherm. Res., 183, 76-83, doi:10.1016/j.jvolgeores.2009.02.013, 2009.

Sigmundsson, F., Hreinsdóttir, S., Hooper, A., Árnadóttir, T., Pedersen, R., Roberts, M. J., Óskarsson, N., Auriac, A., Decriem, J., Einarsson, P., Geirsson, H., Hensch, M., Ófeigsson, B. G., Sturkell, E., Sveinbjórnsson, H., and Feigl, K. L.: Intrusion triggering of the 2010 Eyjafjallajókull explosive eruption, Nature, 468, 426-430, doi:10.1038/nature09558, 2010.

Smithsonian Institution, Global Volcanism Program, available at: http://www.volcano.si.edu, 2014.

Stork, D. and Hassibi, B.: Second order derivatives for network pruning: Optimal Brain Surgeon, in: Advances in Neural Information Processing Systems 5, edited by: Hanson, S. J., Cowan, J. D., and Giles, C. L., Morgan Kaufmann Publishers Inc., San Mateo, 164-171, 1993.

Tupper, A., Carn, S., Davey, J., Kamada, Y., Potts, R., Prata, F., and Tokuno, M.: An evaluation of volcanic cloud detection techniques during recent significant eruptions in the western 'Ring of Fire', Remote Sens. Environ., 91, 27-46, 2004.

Wallace, P.: Volcanic $\mathrm{SO}_{2}$ emissions and the abundance and distribution of exsolved gas in magmas, J. Volcanol. Geotherm. Res., 108, 85-106, 2001.

Watson, I. M., Realmuto, V. J., Rose, W. I., Prata, A. J., Bluth, G. J. S., Gu, Y., Bader, C. E., and Yu, T.: Thermal infrared remote sensing of volcanic emissions using the moderate resolution imaging spectroradiometer, J. Volcanol. Geotherm. Res., 135, 75-89, 2004.

Wen, S. and Rose, W. I.: Retrieval of sizes and total masses of particles in volcanic clouds using AVHRR bands 4 and 5, J. Geophys. Res., 99, 5421-5431, 1994.

Yu, T., Rose, W. I., and Prata, A.: Atmospheric correction for satellite-based volcanic ash mapping and retrievals using "split window" IR data from GOES and AVHRR, J. Geophys. Res., 107, 4311, doi:10.1029/2001JD000706, 2002.

Zehner, C. (Ed.): Monitoring Volcanic Ash from Space, Proceedings of the ESA-EUMETSAT workshop on the 14 April to 23 May 2010 eruption at the Eyjafjoll volcano, South Iceland, Frascati, Italy, ESA-Publication STM-280, doi:10.5270/atmch-1001, 26-27 May 2010. 